\title{
Tratamiento de las
}

políticas antidumping

en el marco de la OMC

y los Tratados de Libre

Comercio firmados y

ratificados por Colombia

con Canadá, República

de Corea y Estados

Unidos de América ${ }^{1}$

Treatment of Anti-Dumping Policies Within the Framework of the WTO and Free Trades Agreements Signed and Ratified by Colombia with Canada, Republic Of Korea and The United States of America

Ana María Pineda Cely²

1 Fecha de recepción: 12 de febrero de 2016. Fecha de aceptación: 21 de junio de 2016. Para citar el artículo: Pineda, A. "Tratamiento de las Políticas Antidumping en el Marco de la OMC y los Tratados de Libre Comercio Firmados y Ratificados por Colombia con Canadá, República de Corea y Estados Unidos de América". Revist@ E-Mercatoria,vol. 15, No 1, enero-junio, 2016. DOI: https://doi.org/10.18601/16923960.v15n1.02

2 Coordinadora en el Departamento de Derecho Comercial de la Universidad Externado de Colombia. Abogada de la Universidad Externado de Colombia y Especialista en Derecho Comercial de la misma casa de estudios. Contacto: ana.pineda@uexternado.edu.co 


\section{RESUMEN}

Los acuerdos de libre comercio (TLC) se han convertido en una importante herramienta para el desarrollo de la vida comercial y social de las naciones, ya que promueven la reducción de aranceles, la producción y la promoción del crecimiento económico del país, pero además abren la puerta a la generación de economías a escala, a la especialización de la producción interna y al aumento del comercio nacional.

Es por esto que hoy por hoy resulta de particular importancia estudiar el marco regulatorio de dichos acuerdos que puede enfocarse en distintos aspectos, por lo que el presente documento abordará el análisis de uno de ellos, esto es, de las políticas y normas dirigidas a corregir y eliminar los efectos negativos que las prácticas desleales o prácticas dumping que pueden llegar a causar en el desarrollo del país y de las empresas nacionales.

Palabras clave: relaciones comerciales, política de competencia, tratado de libre comercio, Organización Mundial del Comercio, prácticas dumping, precios, exportación, importación, arancel, medidas de protección, competitividad.

\section{ABSTRACT}

The Free Trade Agreements (FTA) have become an important tool for the commercial and social development of the nations, that promotes the reduction of taxes, production and promotion of economic growth, and also opens the door to generate economies of scale, specialization of domestic production and increases domestic trade.

That's why today is particularly important the study of the regulatory framekwork of such Agreements, which includes different and varied aspects. This document will try to focus in just one of them, which is the norms and policies directed to correct and eliminate the negative effects that dumpin practices may cause in the country and the national companies development.

Key words: trade relationships, competition policy, free trade agreements, World Trade Organization, dumping practices, prices, fees, exportation, importation, tax, protection measures, competitiveness.

\section{INTRODUCCIÓN}

La apertura comercial y las nuevas condiciones de competencia que surgen en un mercado globalizado, crean ambientes propicios para que se generen nuevas prácticas que atentan contra la libre y leal competencia y que imposibilitan el crecimiento de las empresas nacionales. Estas situaciones cada vez 
más frecuentes han generado la reacción de los Gobiernos y de las organizaciones multilaterales e internacionales que buscan por medio de políticas y normas corregir estas prácticas desleales y garantizar que la fijación de los precios responda al funcionamiento libre del mercado y de la competencia.

Las prácticas desleales como el Dumping ${ }^{3}$ pueden causar daños irremediables en el desarrollo del país y de las empresas nacionales, afectando tanto la economía en general como sectores específicos de la misma con efectos nocivos que se reflejan en los consumidores. Con el fin de evitar estas situaciones, se han venido creando diversos instrumentos dirigidos a regular y prohibir esta clase de prácticas, como también a garantizar la libre y leal competencia en las relaciones comerciales.

A nivel internacional la Organización Mundial del Comercio (en adelante $\mathrm{OMC}$ ) es el organismo encargado de establecer una normatividad ordenada y coherente que evite la producción de las prácticas desleales, así como de implementar los mecanismos a través de los cuales se contrarrestan los efectos negativos que derivan de ellas, a través de la imposición de investigaciones, medidas y derechos antidumping de conformidad con lo establecido en el artículo VI del GATT' de $1994^{5}$ y el Acuerdo relativo a la aplicación del artículo VI del GATT de 1994.

3 El Dumping es una práctica que se desarrolla a nivel del comercio internacional y que consiste en la discriminación de precios que se presenta cuando se exporta un producto a un precio menor (denominado "valor de exportación") frente al valor normal que un productor similar tiene dentro del mercado del país que lo recibe (denominado "precio normal"). Para ver más sobre este tema consultar: https://www.mincomercio.gov.co/descargar.php?id=24462, www.comunidadandina.org/competencia/dumping.htm, http:// www.wto.org/spanish/tratop s/adp s/adp info s.htm

4 El GATT (General Agreement on Tariffs and Trade), es el Acuerdo General sobre Tarifa y Comercio ha sido reemplazado por la Organización Mundial del Comercio. FIGUEROA CASTRO A. Manual de Exportaciones, La Exportación en Colombia. Universidad del Rosario, Facultad de Administración, Bogotá, Colombia. p.283.

5 "El GATT de 1994 establece una serie de principios fundamentales aplicables al comercio entre los Miembros de la OMC, incluido el principio de la "nación más favorecida". En él se establece también que los productos importados no estarán sujetos a impuestos u otras cargas interiores superiores a los aplicados a los productos nacionales ni recibirán en otros aspectos un trato menos favorable que el dispensado a los productos nacionales en virtud de las leyes y reglamentos internos; se establecen asimismo normas relativas a las restricciones cuantitativas, los derechos y formalidades referentes a la importación, y la valoración en aduana. Los Miembros de la OMC convinieron también en el establecimiento de listas de tipos arancelarios consolidados. Por otro lado, el artículo VI del GATT de 1994 autoriza expresamente la imposición de un derecho Antidumping específico a las importaciones procedentes de un determinado país, por encima de los tipos consolidados, en los casos en que el Dumping cause o amenace causar daño a una rama de producción nacional o retrase de manera importante la creación de una rama de producción nacional. El Acuerdo relativo a la Aplicación del artículo VI del GATT de 1994, conocido corrientemente por el nombre de Acuerdo Antidumping ("Acuerdo AD"), desarrolla los principios fundamentales establecidos en el artículo VI con miras a su aplicación a la investigación, determinación y aplicación de derechos Antidumping". ORGANIZACIÓN MUNDIAL 
A nivel bilateral los instrumentos de protección y promoción de la competencia se han incorporado dentro de los Tratados de Libre Comercio (en adelante TLC) que constituyen no sólo un objetivo a alcanzar, sino una obligación de las partes suscribientes. Cabe resaltar que a la fecha Colombia tiene trece (13) Acuerdos comerciales vigentes $^{6} \mathrm{y}$ ha suscrito en la última década TLC con Corea del Sur ${ }^{7}$, Costa Rica $^{8}$, Israel ${ }^{9}$

DEL COMERCIO. Información Técnica sobre las Medidas Antidumping., consultado el 18 de Agosto de 2012, en: http://www.wto.org/spanish/tratop_s/adp_s/adp_info_s.htm

6 En la actualidad Colombia tiene Acuerdos comerciales vigentes con México, los países miembros del triángulo del norte (El Salvador, Guatemala y Honduras), los países miembros de la Comunidad Andina (Bolivia, Colombia, Ecuador y Perú), los doce países miembros que integran el Acuerdo Principal sobre Comercio y Cooperación Económica y Técnica entre la República de Colombia y la Comunidad del Caribe (CAPRICOM), el Acuerdo de Complementación Económica N 59 (ACE 59) - MERCOSUR, Chile, Acuerdo de Libre Comercio entre la República de Colombia y los Estados AELC (EFTA), Canadá, Estados Unidos, Venezuela, Cuba, Nicaragua y la Unión Europea. Para profundizar consulte: MINISTERIO DE INDUSTRIA, COMERCIO Y TURISMO. Acuerdo Comercial y de Inversión, Acuerdos Vigentes, consultado el 19 de agosto de 2014, en: http://www.tlc.gov. co/publicaciones. php?id $=5398$.

7 Las conversaciones entre Colombia y Corea del Sur que dieron lugar a la firma del TLC comenzaron en el año 2009 en la capital de Seúl y culminaron el 21 de febrero de 2013 con la firma del Ministro de Comercio de Corea del Sur Bark Taeho y el Ministro de Comercio de Colombia Sergio Díaz Granados en ésta misma ciudad. El mencionado Acuerdo comercial deberá pasar por un análisis de constitucionalidad que adelantarán las autoridades competentes de cada país parte del Acuerdo. En el capítulo 7 están ubicadas las medidas de protección de la competencia y prácticas Dumping, denominado "Defensa Comercial" y se encuentra dividido en 2 secciones, la sección A que abarca la regulación correspondiente a las "Medidas de Salvaguardia" y la sección B que establece toda la normatividad sobre las "Medidas Antidumping y Compensatorias". Para profundizar consulte: Cfr. pág. 61.

8 "En mayo de 2012 durante la V reunión de Alianza Pacifico en la ciudad de Bogotá se impulsó la idea de un TLC entre los dos países. Este Acuerdo cobra aún más relevancia, dado el interés de Costa Rica por hacer parte de la Alianza Pacífico, instancia en la que se terminarán de discutir los asuntos de interés multilateral. Posteriormente, el 15 de junio de 2012 el Presidente Santos y la Presidenta Chinchilla lanzaron el inicio de las negociaciones para un TLC entre ambos países" [...] "El proceso de negociación se adelantó en cuatro rondas y finalizó en marzo pasado. La firma del Acuerdo se llevó acabo el 22 de mayo en el marco de la VII Ronda de la Alianza del Pacífico Ministerio de Comercio Industria y Turismo" [...] "el Acuerdo fue firmado por las partes y deberá someterse a la aprobación de los respectivos Congresos. [...] Dentro de los 22 temas que abarca el Acuerdo se incluye: [...] Transparencia, Reglas de Origen y procedimientos aduaneros relacionados con el origen [...], Obstáculos técnicos al comercio, Facilitación de Comercio y procedimientos aduaneros, $[\ldots]$ Propiedad Intelectual, Competencia, Comercio electrónico, [...] entre otros. Las disposiciones en estos capítulos, buscan crear mejores condiciones para el intercambio de bienes, servicios e inversión" MINISTERIO DE COMERCIO INDUSTRIA Y TURISMO. ABC del Acuerdo Comercial Colombia con Costa Rica consultado el 19 de agosto de 2014, en: http://www. mincit.gov.co/publicaciones.php?id=5812.

9 Israel tiene una orientación comercial similar a la agenda comercial de Colombia. Ha firmado un Acuerdo de Asociación con la Unión Europea (1992) y Turquía (1997). En 1992 firmó un Acuerdo de Libre Comercio con los países de EFTA. Cuenta con Tratados de Libre Comercio con los Estados Unidos (1985, 1996), Canadá (1996) y México (2000). 
y Panamá. ${ }^{10}$ Este artículo analiza en primer lugar, la forma en la que se encuentra regulado el derecho y las medidas antidumping en la Organización Mundial del Comercio así como las herramientas dispuestas para enfrentar las situaciones en las cuales se configura esta práctica. En segundo lugar, se estudia la regulación de las prácticas de Dumping establecidas en los tratados y convenios comerciales internacionales firmados y ratificados por Colombia con La República de Corea, Canadá y Estados Unidos de Norteamérica, con el fin de establecer la forma en la que estos Acuerdos regulan el tema y adoptan medidas para prevenir las conductas desleales y anticompetitivas. Finalmente, este artículo aborda con sentido crítico la manera como Colombia ha venido enfrentando y regulando el Dumping por ser esta una conducta que perjudica las relaciones comerciales y las industrias nacionales.

Recientemente ha puesto en vigor un Tratado de Libre Comercio con MERCOSUR (Uruguay 2009 - Brasil 2010, Paraguay 2010, Argentina 2011). [...] El TLC con Colombia es el único Acuerdo de última generación que incluye disciplinas como inversión, servicios, cooperación y compras públicas. La inclusión de estas disciplinas amplía el alcance e impacto del Acuerdo". [...]El proceso de negociación inició en marzo del año 2012 y se adelantó en cinco rondas. El cierre de la negociación se llevó a cabo en junio de 2013. [...] Los países han acordado suscribir el Acuerdo en Jerusalén a finales de septiembre del presente año. Posteriormente, se someterá a consideración de los respectivos Congresos para su aprobación y, en el caso de Colombia, también de la Corte Constitucional. Surtidos estos trámites el Acuerdo de Libre Comercio con Israel entraría en vigencia. [...] El Acuerdo incluye 16 capítulos, entre otros [...], Obstáculos Técnicos al Comercio, [...]; Defensa Comercial, Servicios, Inversión, Compras Públicas, Asistencia Técnica y Fortalecimiento de las Capacidades Comerciales, Excepciones, Solución de controversias y Disposiciones finales. Las disposiciones pactadas en estas áreas, buscan crear mejores condiciones para el intercambio de bienes, servicios e inversión" MINISTERIO DE COMERCIO INDUS TRIA Y TURISMO. ABC del Acuerdo Comercial Colombia con Israel, consultado el 19 de agosto de 2014, en: http://www.tlc.gov.co/publicaciones.php?id=8047.

10 "Las negociaciones para un TLC con Panamá iniciaron en marzo de 2010. Con esta negociación Colombia busca fortalecer sus lazos comerciales con uno de sus socios naturales por tratarse de un país limítrofe y por la complementariedad de economías. El crecimiento económico de Panamá ba sido bastante dinámico en los últimos años y se está consolidando como un centro de negocios de la región, circunstancia que brinda oportunidades muy interesantes para la industria colombiana". MINISTERIO DE COMERCIO INDUSTRIA Y TURISMO. Acuerdo Comercial entre Colombia con Panamá, consultado el 19 de agosto de 2014, en: http://www.tlc.gov.co/publicaciones.php?id=1252. "El proceso de negociación se adelantó en siete rondas y una mini ronda, finalizando en mayo de 2013. [...]. Este Acuerdo comercial cuenta con 23 capítulos y el Preámbulo, entre los cuales está [...] Medidas de Defensa Comercial, Compras Públicas, Política de Competencia, Comercio Transfronterizos de Servicios, [...] Comercio Electrónico, Inversión, Propiedad Intelectual, Cooperación y Fortalecimiento de las Capacidades Comerciales, Ambiental [...]. MINISTERIO DE COMERCIO INDUSTRIA Y TURISMO. ABC del Acuerdo Comercial Colombia con Panamá, consultado el 19 de agosto de 2014, en: http://www.mincit.gov.co/tlc/publicaciones.php?id=7974. 


\section{LA PROTECCIÓN DE LA COMPETENCIA EN EL MARCO DE LA OMC}

\subsection{ANTECEDENTES DE LA POLÍTICA DE COMPETENCIA INTERNACIONAL establecida por la Organización Mundial del Comercio - OMC}

La Organización Mundial del Comercio (OMC) es un organismo internacional que surgió como consecuencia de un ciclo de negociaciones que iniciaron en el marco del Acuerdo General sobre Aranceles Aduaneros y Comercio (GATT) y en la "Ronda de Uruguay" de 1986 y que en la actualidad se desenvuelven en el foro de nuevas negociaciones del "Programa de Doba para el Desarrollo".

Actualmente la OMC está compuesta por 150 países y otros 30 que se encuentran en proceso de adhesión; sus funciones se materializan en la adopción de decisiones a las que se llega por el consenso de los Países Miembros o por una votación mayoritaria que después es ratificada por los respectivos Parlamentos.

Este organismo fue creado bajo la premisa de sentar los pilares sobre los cuales se va encaminar la normatividad encargada de regular las relaciones comerciales que se efectúen a nivel internacional entre los agentes que intervienen en el mercado, esto es, productores, exportadores e importadores. Igualmente busca generar espacios de resolución de conflictos que permitan que la apertura del comercio fluya con la mayor libertad posible y contribuya al desarrollo económico y social de los países, procurando que las relaciones comerciales internacionales se desenvuelvan de forma leal, equitativa y transparente.

En desarrollo de sus objetivos y su misión, la OMC estableció la Conferencia Ministerial de Singapur de 1996 dedicada al estudio de la política de promoción y protección de la competencia. Así mismo, por medio del Programa Doha para el Desarrollo"1 emprendió la regulación de cuatro temas centrales que

11 La Ronda de Doba es la ronda de negociaciones comerciales más reciente entre los Miembros de la OMC. Tiene por objeto lograr una importante reforma del sistema de comercio internacional mediante el establecimiento de medidas encaminadas a reducir los obstáculos al comercio y de normas comerciales revisadas. La Ronda se denomina también semioficialmente el Programa de Doha para el Desarrollo, ya que uno de sus objetivos fundamentales es mejorar las perspectivas comerciales de los países en desarrollo". "La Ronda se inició oficialmente en la Cuarta Conferencia Ministerial de la OMC, celebrada en Doba (Qatar) en noviembre de 2001. La Declaración Ministerial de Doha establecía el mandato para las negociaciones, entre ellas las relativas a la agricultura, los servicios y un tema de propiedad intelectual, que babian comenzado antes": ORGANIZACIÓN MUNDIAL DEL COMERCIO. La Ronda de Doba, consultado el 23 de Julio de 2013, en: http://www.wto.org/spanish/tratop_s/dda_s/dda_s.htm

"La Quinta Conferencia Ministerial, celebrada en Cancún (México) en septiembre de 2003, quería ser una reunión de balance donde los Miembros acordaran la manera de ultimar el resto de las negociaciones. Pero la reunión se agrió debido a la discordia acerca de las cuestiones agrícolas, incluido el algodón, y se estancó sobre los "temas de Singapur". No se apreciaron progresos reales sobre los temas de Singapur y en agricultura basta las primeras boras del $1^{\circ}$ de agosto de 2004, momento en que el Consejo General adoptó una serie de decisiones (en ocasiones llamada el "Paquete de Julio"). Se incumplió el plazo inicial del $1^{\circ}$ de 
se agruparon en los denominados "temas de Singapur" a través de los cuales regula la política de protección de la competencia internacional establecida por la OMC así: "el comercio e inversiones, la política de competencia, la transparencia de la contratación pública y las formas de simplificar los procedimientos comerciales". Los tres primeros se repartieron en tres grupos de trabajo y el último tema denominado "facilitación del comercio" le fue asignado al Consejo del Comercio de Mercancías de la $\mathrm{OMC}^{12}$

Los cuatro temas mencionados también se encontraban incorporados en el Programa de Doha para el Desarrollo, pero después de la Conferencia Ministerial de Cancún (2003) por la falta de negociaciones, se decidió el $1^{\circ}$ de agosto de 2004, eliminar los tres temas restantes del programa y se acordó continuar únicamente con el tema de "la facilitación del comercio".13

Al respecto es importante señalar que la OMC no regula las acciones anticompetitivas en las que incurren los empresarios, sino que por medio de acuerdos multilaterales otorga las herramientas para que los Estados puedan enfrentar el ejercicio de éstas prácticas y, con esto, garantiza que los Gobiernos se comprometan a mantener una competencia sana, leal y libre de obstáculos. En efecto, la mayoría de estos Acuerdos fueron el resultado de las negociaciones efectuadas en 1986 en la Ronda de Uruguay en las que se incluyeron los pactos del Acuerdo General sobre Aranceles Aduaneros y Comercio de 1994 (GATT, por sus siglas en inglés) y el Acuerdo General sobre el Comercio de Servicios (AGCS).

Por su parte, el Gobierno Colombiano ha venido incorporando éstas herramientas de protección a la competencia desleal por medio de la expedición diferentes Decretos que regulan las medidas antidumping y los derechos compen-

enero de 2005. Después de ello, los Miembros se propusieron de manera no oficial concluir las negociaciones para el final de 2006, nuevamente sin éxito. En la Conferencia Ministerial de Hong Kong celebrada en diciembre de 2005 se lograron reducir las divergencias entre los Miembros, pero siguió babiendo algunas diferencias insuperables, y el Director General Pascal Lamy suspendió las negociaciones en julio de 2006. A principios de 2007 se bicieron esfuerzos para tratar de lograr avances significativos": ORGANIZACIÓN MUNDIAL DEL COMERCIO. La Ronda de Doba., consultado el 23 de Julio de 2013, en: http://www.wto.org/spanish/thewto_s/whatis_s/tif_s/doha1_s.htm

12 ORGANIZACIÓN MUNDIAL DEL COMERCIO. Inversiones, Competencia, Contratación pública, Procedimientos Simplificados, consultado el 19 de Mayo de 2012, en: http://www.wto. org/spanish/thewto_s/whatis_s/tif_s/bey3 s.htm\#investment

13 La OMC define la "facilitación del comercio" como la "Supresión de obstáculos al movimiento transfronterizo de mercancías (por ejemplo, simplificación de los procedimientos aduaneros)" ORGANIZACIÓN MUNDIAL DEL COMERCIO. Glosario de Términos, consultado el 20 de Agosto de 2014, en: http://www.wto.org/spanish/thewto_s/glossary_s/glossary_s.htm. Adicionalmente es importante señalar que "El Acuerdo sobre Facilitación del Comercio contiene disposiciones para que los procedimientos aduaneros sean más rápidos y eficientes mediante la cooperación efectiva entre las autoridades aduaneras y otras autoridades competentes en las cuestiones relativas a la facilitación del comercio y el cumplimiento de los procedimientos aduaneros. También contiene disposiciones sobre asistencia técnica y creación de capacidad en esta esfera" ORGANIZACIÓN MUNDIAL DEL COMERCIO. Glosario de Términos., consultado el 20 de Agosto de 2014, en: http://www.wto.org/spanish/tratop_s/ tradfa $\mathrm{s} /$ tradfa $\mathrm{s} . \mathrm{htm}$ 
satorios, el primero de ellos fue el Decreto 1500 de 1990 y luego siguieron los Decretos 2444 de 1990, 150 de 1993 y 299 de 1995. Posteriormente, el Ministerio de Comercio, Industria y Turismo reguló únicamente la aplicación de los derechos antidumping en las importaciones derivadas de los países miembros de la OMC a través del Decreto 991 de 1998 derogado por el Decreto 2550 de 2010 en cual fue incorporado en la legislación colombiana por medio de la Ley 170 de $1994 .{ }^{14}$

\subsection{La Regulación sobre el Dumping establecida Por la Organización Mundial del Comercio}

En materia de protección a la competencia desleal la OMC expidió el Acuerdo relativo a la aplicación del artículo VI del Acuerdo General sobre Aranceles Aduaneros y Comercio de 1994 (Acuerdo Antidumping) en el que se establece el procedimiento para determinar cuándo un producto es objeto de Dumping y las medidas que existen para contrarrestar sus efectos.

Se observa que la OMC no obliga a los Países Miembro a imponer derechos antidumping ni a que incorporen un marco jurídico que reglamente la imposición de los mismos, pero en caso de que quieran hacerlo el Acuerdo plantea que las medidas antidumping solo se aplicarán cuando se den los supuestos previstos por el artículo VI del GATT de 1994, que a continuación se exponen y que groso modo plantean que sólo puede aplicarse medidas correctivas cuando estas prácticas causen o amenacen con causar daños importantes o graves a una rama de la producción nacional.

En Colombia la autoridad competente para darle trámite a las solicitudes de investigación de prácticas Dumping es el Ministerio de Comercio, Industria y Turismo, concretamente la Dirección de Comercio Exterior (DCE) que está conformada por varias subdirecciones, entre las cuales está la de Prácticas Comerciales y se encarga de adelantar las investigaciones correspondientes a las prácticas desleales de comercio internacional ${ }^{15} \mathrm{y}$ de garantizar la protección a la producción nacional de los efectos negativos que produzcan. ${ }^{16}$

14 MINISTERIO DE COMERCIO EXTERIOR. Guía de Dumping y Subsidios en Colombia (2001), Bogotá, p. 9, y MINISTERIO DE COMERCIO, INDUSTRIA Y COMERCIO. Dirección de Comercio Exterior, Subdirección de Prácticas Comerciales, Dumping y Subsidios (2010), Bogotá, p. 7.

15 Para el 18 de julio del año 2014 se reporta que hay 5 investigaciones de prácticas Dumping en curso, 12 investigaciones con aplicación de los derechos vigentes, 28 investigaciones con derechos ya expirados, 28 investigaciones adelantadas sin aplicación de derechos y 3 investigaciones solicitadas sin apertura. MINISTERIO DE COMERCIO, INDUSTRIA Y TURISMO, Dumping, Resumen de investigaciones Antidumping Adelantadas por Colombia, consultado el 30 de septiembre de 2014, en: http://www.mincit.gov.co/publicaciones. php?id= 12207 .

16 Al respecto véase caso Colombia - República popular de China, Informe Ministerio de Comercio, Industria y Turismo, Subdirección de Prácticas Comerciales "evaluación técnica 
Atendiendo a lo anterior, el procedimiento para poder adoptar medidas de salvaguarda inicia con una solicitud escrita que debe presentar la rama de producción nacional ${ }^{17} \mathrm{o}$ el Gobierno en nombre de ella, en la que se incluirán las pruebas que se consideren pertinentes sobre:

\section{a. La existencia del Dumping.}

El artículo 2 de la Parte 1 del Acuerdo de la OMC establece que las partes contratantes deben probar uno de los siguientes casos:

- Que en el curso de operaciones comerciales normales se introduce en el mercado de destino un producto a un precio inferior al de su valor normal frente a un producto similar destinado al consumo en el país exportador.

- En caso de que exista una situación especial del mercado que permita concluir que el producto similar no está incurso en una operación mercantil normal, el parámetro de comparación será el precio al que se exporte un producto similar a un tercer país apropiado siempre que éste precio sea representativo o con el costo de producción en el país de origen más una cantidad razonable tal y como se señaló anteriormente.

- Cuando no exista precio de exportación o éste no sea confiable por existir un Acuerdo de compensación se construye un precio basado en el valor al que se revendan por primera vez a un comprador independiente los productos importados y en caso de que esto no sea posible la base será establecida por una autoridad competente.

Adicionalmente se debe realizar una comparación entre el valor normal y el precio de exportación, para lo cual se debe aplicar todo el procedimiento expuesto anteriormente, teniendo en cuenta cada una de las circunstancias particulares que se puedan presentar y que influyan en la comparabilidad equitativa de los precios como por ejemplo, las diferencias en las condiciones de venta, las de tributación, entre otros.

del mérito para la imposición de derechos Antidumping definitivos dentro de la etapa final de la investigación por supuesto Dumping en las importaciones de tubos de entubación casing o de producción tubing sin costura clasificados por la subpartida arancelaria 7304.29.00.00 originarios de la república popular china" MINISTERIO DE COMERCIO, INDUSTRIA Y TURISMO. Resolución 0026 de enero 5 de 2012, "Por la cual se resuelve una solicitud de Revocatoria Directa", Bogotá.

17 La expresión "rama de producción nacional" se entenderá en el sentido de abarcar el conjunto de productores nacionales de los productos similares, o aquellos de entre ellos cuya producción conjunta constituya una proporción importante de la producción nacional total de dichos productos. Acuerdo relativo a la aplicación del artículo VI del Acuerdo General sobre Aranceles Aduaneros y Comercio de 1994, Parte 1, Artículo 4, Inciso 1. 


\section{b. Demostrar que el Dumping está causando o amenaza con causar un daño importante a una rama de la producción nacional ${ }^{18}$}

El Acuerdo no regula el ejercicio de las prácticas desleales sino que estudia el Dumping que causa o amenaza con causar un daño a un sector de la economía nacional. El artículo 3 de la parte primera del Acuerdo impone dos vías a las que pueden acudir las partes interesadas:

- Establece que para demostrar la existencia del daño causado por estas prácticas, el Gobierno debe fundamentar la solicitud en pruebas positivas y en un examen objetivo sobre el volumen de las importaciones objeto de Dumping y el efecto de éstas en los mercados locales para los productores nacionales y los productos similares del mercado interno.

- Por otro lado, otorga la posibilidad de que los Estados se anticipen y protejan sus economías antes de que el Dumping cause un daño en la producción nacional, para lo cual el inciso séptimo del artículo 3 de la parte primera del Acuerdo dispone que el Gobierno debe demostrar que se trata de hechos y no de simples conjeturas o posibilidades remotas, por ésta razón las autoridades investigadoras deben analizar que los factores que se exponen a continuación se presentan de forma concurrente y permiten concluir que existe la inminencia de que aparezcan prácticas de competencia desleal que causen un daño importante en alguna rama de la producción del mercado interno.

Por ende, la determinación de la existencia de una amenaza de daño requiere del análisis pormenorizado de los factores que se exponen a continuación y que establece el inciso 3.7 del artículo tercero de la primera parte del Acuerdo:

i. "una tasa significativa de incremento de las importaciones objeto de Dumping en el mercado interno que indique la probabilidad de que aumenten sustancialmente las importaciones;

ii. una suficiente capacidad libremente disponible del exportador o un aumento inminente y sustancial de la misma que indique la probabilidad de un aumento sustancial de las exportaciones objeto de Dumping al mercado del Miembro importador, teniendo en cuenta la existencia de otros mercados de exportación que puedan absorber el posible aumento de las exportaciones;

iii. el hecho de que las importaciones se realicen a precios que tendrán en los precios internos el efecto de hacerlos bajar o contener su subida de manera significativa, y que probablemente hagan aumentar la demanda de nuevas importaciones ${ }_{i}$ y

iv. las existencias del producto objeto de la investigación".

18 Recordar que entre más bajo sea el precio de exportación frente al precio del mercado del país del exportador más alto será el efecto negativo del Dumping. 
Lo anterior permite deducir que el Acuerdo crea instrumentos remediales que atacan el problema y buscan corregir las prácticas que limitan el ejercicio de libre y leal de la competencia con un efecto resarcitorio cuando el daño ya se ha producido, o bien con un efecto preventivo cuando se demuestra que una rama de la producción está expuesta a un daño grave.

\section{c. Existencia de una relación causal entre las importaciones objeto de Dumping y el supuesto daño.}

Adicional a lo anterior, el Acuerdo de la OMC establece que deben haber pruebas objetivas que demuestren la existencia de un nexo causal entre las importaciones y el daño grave o la amenaza del mismo a una rama o sector de la producción nacional, para lo cual es necesario que las autoridades competentes aporten todos los elementos probatorios pertinentes. Señala, además, que cuando aparezcan otros factores diferentes al aumento de las importaciones, que a la vez provoquen daños en la rama de la producción nacional éstos no se atribuirán a las importaciones objeto de Dumping.

Es importante señalar que, contrario a lo que señalamos arriba, en la propuesta inicial de la Ronda de Uruguay se pretendió que las importaciones fueran la base fundamental del daño.

El artículo 3.5 del Acuerdo de la OMC literalmente señala:

Entre los factores que pueden ser pertinentes a este respecto figuran el volumen y los precios de las importaciones no vendidas a precios de Dumping, la contracción de la demanda o variaciones de la estructura del consumo, las prácticas comerciales restrictivas de los productores extranjeros y nacionales y la competencia entre unos y otros, la evolución de la tecnología y los resultados de la actividad exportadora y la productividad de la rama de producción nacional.

\subsection{Reglas especiales para imponer Medidas Provisionales}

Las medidas provisionales son aquellas que se imponen por la necesidad de evitar que se cause un daño grave a la producción nacional durante el adelantamiento de una investigación, y operan siempre que en la determinación preliminar se concluya la existencia de prácticas Dumping que están afectando la industria nacional.

En el artículo 7.1 de la Parte 1 del Acuerdo de la OMC se establecen tres requisitos para imponer una medida provisional correctiva del Dumping, de la siguiente manera:

i. Se ha iniciado una investigación de conformidad con las disposiciones del artículo 5 , se ha dado un aviso público a tal efecto y se han dado a las partes interesadas oportunidades adecuadas de presentar información y hacer observaciones; 
ii. Se ha llegado a una determinación preliminar positiva de la existencia de Dumping y del consiguiente daño a una rama de producción nacional;

iii. La autoridad competente juzga que tales medidas son necesarias para impedir que se cause daño durante la investigación ${ }^{19}$.

El artículo 7.3 de la Parte 1 del Acuerdo establece que las medidas provisionales no podrán ser aplicadas antes de que hayan transcurrido 60 días desde el inicio de la investigación y adicionalmente prohíbe que dichas medidas se extiendan por períodos de tiempo superiores a los 4 meses, salvo que a petición de los exportadores que gozan de una posición relevante en el mercado o por decisión de una autoridad competente dicho periodo sea extendido, siempre que no exceda de los 6 o los 9 meses de conformidad con lo que determinen las autoridades competentes y con las necesidades específicas de cada caso.

\subsubsection{Suspensión anticipada del procedimiento y terminación sin imposición de medidas antidumping}

El Acuerdo de la OMC plantea una forma de suspender o terminar el procedimiento sin que proceda la imposición de medidas proteccionistas, siempre que el exportador comunique que de manera voluntaria asumirá el compromiso alternativo de:

- Revisar sus precios.

- Ponerle fin a las exportaciones en la zona donde se esté adelantando la práctica Dumping.

Lo anterior se da con el fin de que las autoridades se convenzan de que por medio de estos compromisos el país está eliminando los efectos negativos que las prácticas Dumping producen dentro de las relaciones comerciales internacionales.

Pero aún con la existencia de estos compromisos, si las autoridades o si el país exportador lo desea, la investigación deberá adelantarse hasta el final. En este evento los efectos sobre el compromiso asumido serán los siguientes:

Si se llega a una decisión negativa respecto de la existencia del Dumping y el Daño: El Acuerdo establece que el compromiso pactado se eliminará cuando al final se llegue a una decisión negativa respecto de la existencia del Dumping, exceptuando aquellos casos en los que estos compromisos se basen en precios.

Si la conclusión a la que se llega es positiva: El compromiso se mantiene, de conformidad con lo que el Acuerdo establece.

19 ORGANIZACIÓN MUNDIAL DEL COMERCIO, Acuerdo Relativo a la Aplicación del Artículo VI del Acuerdo General sobre Aranceles Aduaneros y Comercio de 1994, consultado el 29 de Julio de 2012, en: http://www.wto.org/spanish/docs_s/legal_s/19-adp_01_s.htm\#ArticleI 


\subsubsection{Imposición de los derechos antidumping y determinación su cuantía}

Los derechos antidumping son un mecanismo que le permiten a los Estados contrarrestar el efecto negativo que produce el desarrollo de las prácticas Dumping y que se adquiere en virtud del "Acuerdo Relativo a la Aplicación del Artículo VI del Acuerdo General sobre Aranceles Aduaneros y Comercio de 1994"

El Acuerdo de la OMC establece que es una facultad atribuida a las autoridades del país importador, teniendo en cuenta que el tratamiento que se efectuara para cada caso en que vaya a imponer una medida debe ser particular y debe excluir cualquier forma de trato discriminatorio que sobre el productor se pudiese llegar a efectuar, excepción hecha de los casos de importaciones sobre las que se hayan pactado compromisos en materia de precios.

El artículo 9.2 del Acuerdo establece que las autoridades investigadoras pueden designar al proveedor del producto o al país proveedor cuando se llegue al establecimiento de un derecho antidumping sobre un producto. Adicionalmente, el artículo 9.3 prohíbe que la cuantía del derecho antidumping supere el margen del Dumping.

El artículo 9.4 es una excepción del artículo 9.3 dado que permite la aplicación de los derechos antidumping a las importaciones de productos que no hayan sido objeto del examen para determinar el margen de Dumping de forma individual, dado que el artículo 6.10 permite que las autoridades de un país limiten su examen a un número de productos cuando éste resulte tan grande que el examen completo resulte imposible. ${ }^{20}$

Finalmente, el artículo 9.5 establece que las autoridades competentes ${ }^{21}$ debe adelantar el presente examen con prontitud en comparación con los demás procedimientos que se adelantan en virtud del presente Acuerdo.

\subsubsection{Término establecido para la duración de las medidas antidumping}

El tiempo de duración de los derechos antidumping y de las medidas establecidas para enfrentar dicha práctica, está delimitado dentro de los parámetros en que la onda negativa de tales prácticas siga aumentando, es decir, que sólo durarán el tiempo que sea necesario para evitar que estas sigan produciendo efectos negativos. En todo caso debe tenerse presente que el tiempo establecido puede ser prorrogado cuando así lo soliciten las autoridades y lo determinen

20 Para profundizar consulte: CONDON J. Bradly. El Derecho de La Organización Mundial del Comercio, Tratados, Jurisprudencia y práctica (2007). Cameron May ltd., Reino Unido, pág. 461.

21 En Colombia la autoridad competente para atender las solicitudes de investigación frente a los casos de imposición de las medidas Antidumping es el Ministerio de Comercio, Industria y Turismo a través de la Subdirección de Prácticas Comerciales. 
las necesidades de cada caso particular, con la limitación de que en todo caso no podrá sobrepasar el plazo de 5 años, salvo los casos en que la necesidad de impedir que la prolongación o repetición del efecto negativo de estas prácticas obligue a las autoridades a prorrogar por más tiempo la medida. La prórroga exige que se cumplan con los requisitos que exige el artículo 11.3 del Acuerdo, a saber:

i. Que las autoridades inicien un examen antes de que expire el plazo de los cinco años por propia iniciativa o a raíz de una petición debidamente fundamentada hecha por o en nombre de la rama de producción nacional con una antelación prudencial a dicha fecha.

ii. Que las autoridades determinen que la supresión del derecho daría lugar a la continuación o la repetición del daño y del Dumping.

Adicionalmente es obligatorio que cuando se vaya a iniciar una investigación contra un país miembro por prácticas Dumping, quien vaya a adelantar dichas investigaciones notifique al país investigado, a las partes interesadas y adicionalmente se realice un aviso público.

\subsubsection{Formas de Revisión Judicial}

Todas las actuaciones que se adelanten dentro de estos procedimientos pueden ser revisadas en los procedimientos judiciales, arbitrales o administrativos con que cuente la legislación nacional de cada país miembro, quienes contarán con independencia frente a las autoridades encargadas de la determinación o examen de que se trate.

\subsubsection{Países Miembro en Desarrollo}

El Acuerdo reconoce la existencia de la posición de desigualdad en la que se encuentran los países miembros cuando uno de ellos tiene un mayor nivel de desarrollo frente a otros, y esta parte es particularmente importante en la medida en que esta es la situación en la que se encuentra Colombia frente a Estados Unidos, Canadá y Corea del Sur países que muestran un claro avance económico, tecnológico y productivo.

El Acuerdo establece, en virtud de tal reconocimiento, que los países miembro que se encuentren en una posición más desarrollada frente a otro deberán tener presente tal situación cuando contemplen la aplicación de medidas antidumping.

De esta manera se regula que previa la aplicación de cualquier medida correctiva de prácticas Dumping se tenga la obligación de examinar si estas medidas pueden llegar a causar daños a los intereses del país en desarrollo, y de 
ser así contemplar las opciones existentes para utilizar soluciones alternativas establecidas en el Acuerdo.

\subsection{7. "El Comité"}

El Acuerdo contempla la creación de un comité, que será denominado "EL COMITÉ", que se encargará de liderar todos los procedimientos que se adelanten sobre las prácticas antidumping y de servir de órgano consultor frente a los países miembros frente a esta materia y los demás fundamentos establecidos dentro del Acuerdo.

El Comité se encuentra compuesto de la siguiente manera:

- Representantes de cada uno de los Miembros.

- Un presidente electo por El Comité, quien se reunirá por lo menos dos veces al año y siempre que lo solicite un país Miembro, cuando este lo considere necesario.

\subsubsection{Prohibiciones}

El acuerdo establece tajantemente la imposibilidad de adoptar medidas correctivas de las prácticas Dumping que no hagan parte de las disposiciones establecidas por el GATT de 1994.

Adicionalmente impide que se realicen reservas de algunas de las disposiciones establecidas en el Acuerdo sin el acuerdo de los demás países miembros.

\subsubsection{Diagrama del procedimiento de la OMC}

1.2.9.1. Inicio de la investigación para determinar la existencia, el grado y los efectos del dumping

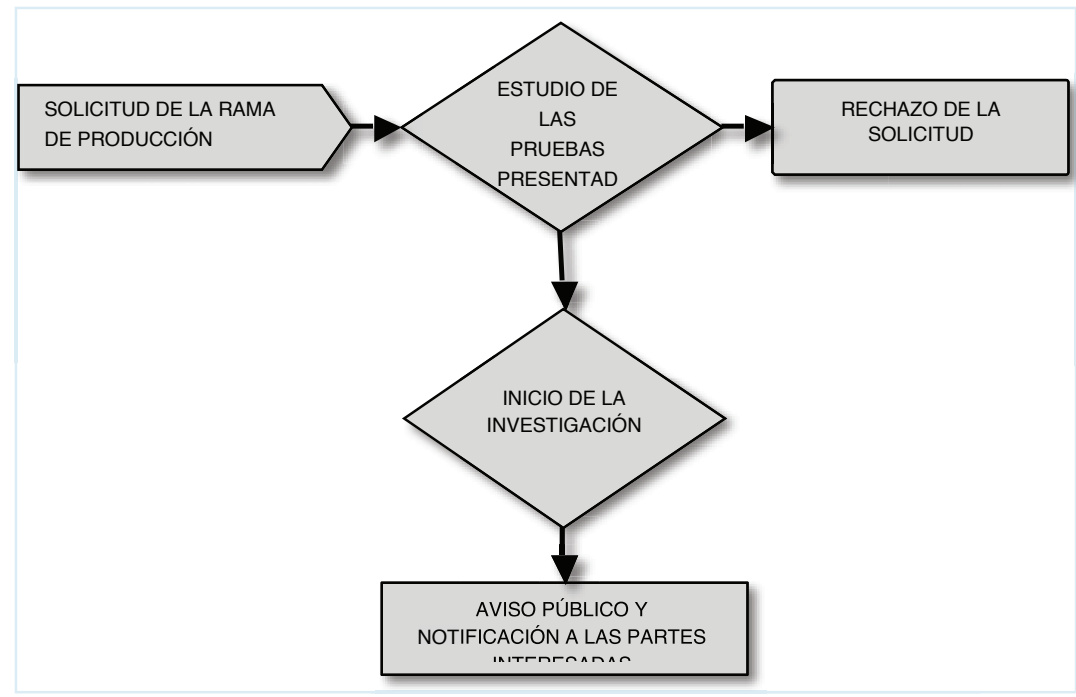




\subsubsection{Determinación Preliminar}

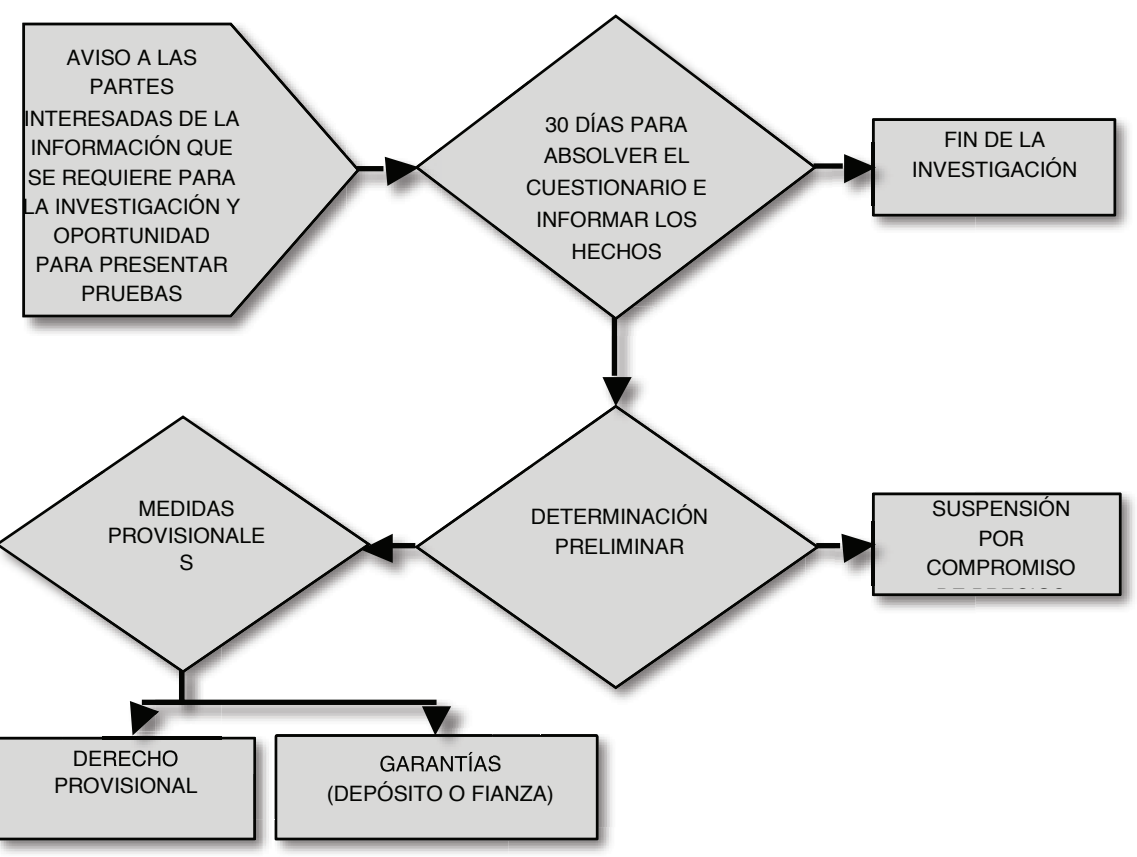

1.2.9.3. Determinación Final

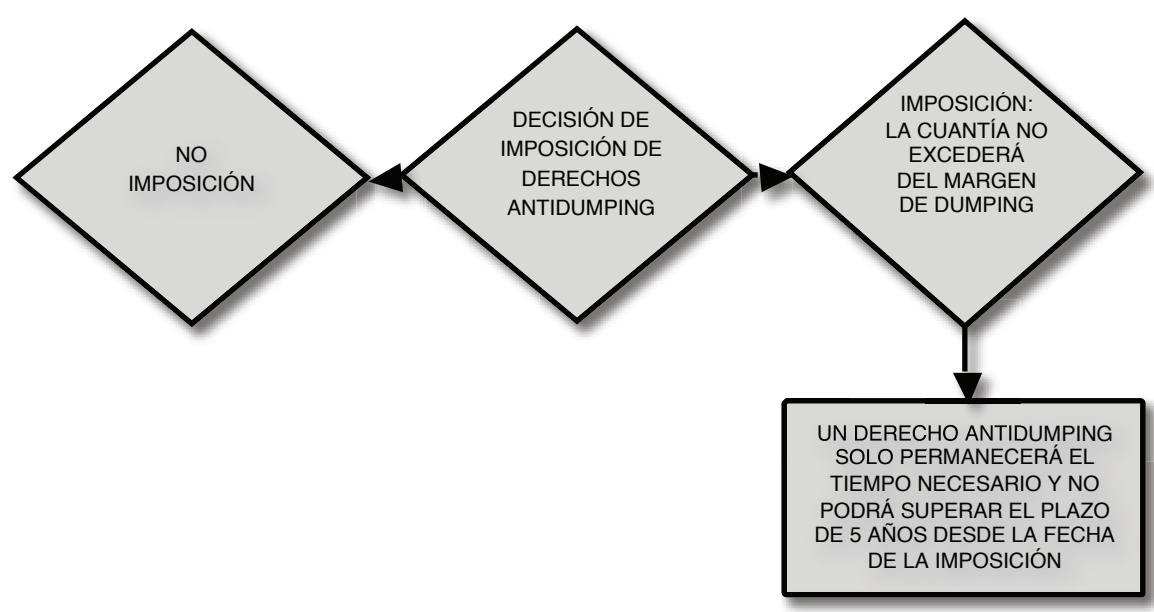




\subsubsection{Aplicación del procedimiento anteriormente analizado a un caso particular}

1.2.10.1 Informe del Grupo Especial: MÉXICO-MEDIDAS ANTIDUMPING, Reclamación con respecto al arroz ${ }^{22}$

La diferencia se presentó entre México y Estados Unidos por la imposición de derechos antidumping por México a las importaciones de "arroz blanco grano largo" procedentes de los Estados Unidos. Los hechos se desenvolvieron así:

"1. El 2 de junio de 2000, el Consejo Mexicano del Arroz, A.C. ("CMA") presentó una petición ante la Secretaría de Comercio y Fomento Industrial ("SECOFI"), quien era el encargado se la aplicación de las disposiciones antidumping de México en ese momento. La iniciación de la investigación se publicó en el Diario Oficial de la Federación de fecha 11 de diciembre de 2000.

2. El período objeto de investigación a efectos de la determinación de la existencia de Dumping abarcó el período comprendido entre el 10 de marzo y el 31 de agosto de 1999. A efectos de la determinación de la existencia de daño, la Secretaría de Economía analizó los datos correspondientes al período de los años 1997, 1998 y 1999. La Secretaría de Economía notificó la iniciación de la investigación a los solicitantes.

3. La Secretaría de Economía publicó su resolución preliminar el 18 de julio de 2001. En ella, la Secretaría de Economía resolvió que Riceland, Rice Company y Farmers Rice no estaban incurriendo en Dumping.

4. El 5 de junio de 2002, la Secretaría de Economía publicó su resolución final. En ella, la Secretaría de Economía no constató prueba alguna de existencia de Dumping en relación con Farmers Rice y Riceland e impuso un derecho del 0 por ciento a esos exportadores. En el caso de Rice Company, la Secretaría de Economía constató un margen de Dumping del 3,93 por ciento e impuso un derecho del 3,93 por ciento. En relación con los restantes exportadores estadounidenses, la Secretaría de Economía impuso un derecho del 10,18 por ciento basada en los hechos de los que tenía conocimiento.

5. El 16 de junio de 2003, el Gobierno de los Estados Unidos solicitó la celebración de consultas con el Gobierno de México de conformidad con el artículo 4 del Entendimiento relativo a las normas y procedimientos por los que se rige la solución de diferencias ("ESD"), el párrafo 1 del artículo XXII del Acuerdo General sobre Aranceles Aduaneros y Comercio de 1994 ("GATT de 1994")."23

22 ORGANIZACIÓN MUNDIAL DEL COMERCIO. Informe del Grupo Especial, México - Medidas Antidumping definitivas sobre la carne de bovino y el arroz, reclamación con respecto al arroz del 6 de junio de 2005, consultado el 18 de agosto de 2012, en: WWW.WTO.ORG/SPANISH/ TRATOP S/DISPU S/295R A S.DOC. pp. 20-30. 
"Los Estados Unidos solicitaron el establecimiento de un grupo especial para que recomiende a México que ponga sus medidas en conformidad con las obligaciones que ha contraído en virtud del Acuerdo Antidumping, el Acuerdo SMC y el GATT de 1994. México solicita al Grupo Especial que emita una resolución preliminar sobre las deficiencias de la solicitud de establecimiento de un grupo especial presentada por los Estados Unidos.

La imposición de derechos antidumping sobre el arroz blanco grano largo originario de los Estados Unidos

La utilización por la Secretaría de Economía de un período objeto de investigación obsoleto infringió el párrafo 2 del artículo VI del GATT de 1994 y el artículo 1 y los párrafos 1, 2, 4 y 5 del artículo 3 del Acuerdo Antidumping:

En el presente caso, la rama de producción solicitante seleccionó el período objeto de investigación que deseaba que la Secretaría de Economía examinara en la investigación antidumping y la evaluación del daño, y aceptó su petición, desechando las objeciones de los exportadores estadounidenses y los importadores. Como consecuencia de ello, hubo un intervalo de más de 15 meses entre el final del período objeto de investigación (agosto de 1999) y la iniciación de la investigación (diciembre de 2000). La Secretaría de Economía ni siquiera recogió, y mucho menos examinó, datos correspondientes a ese período de 15 meses. Cuando el 5 de junio de 2002 la Secretaría de Economía hizo pública su Resolución final, ese intervalo se había ampliado hasta casi tres años.

Esos períodos eran tan remotos entre sí que la información reunida por la autoridad investigadora no podía proporcionar un fundamento para una constatación objetiva de existencia de Dumping, daño y relación causal (tal como se definen y utilizan esos términos en el Acuerdo Antidumping) o una determinación basada en pruebas positivas.

Tampoco disponía de la información que necesitaba para determinar que las importaciones objeto de examen están siendo objeto de Dumping y son la causa del daño importante (o la amenaza) actual a la rama de producción nacional que produce el producto similar.

Por tanto, la imposición de una medida antidumping al arroz blanco grano largo procedente de los Estados Unidos infringió el artículo 1, los párrafos 1, 2, 4 y 5 del artículo 3 del Acuerdo Antidumping, así como el párrafo 2 del artículo VI del GATT de 1994.

La Secretaría de Economía infringió el art. 1, los párrafos 1 y 5 del art. 3 y el párrafo 2 del art. 6 del Acuerdo Antidumping al limitar su examen del daño a sólo seis meses de 1997, 1998 y 1999." 24 


\section{CONSIDERACIONES GENERALES SOBRE LA REGULACIÓN DEL DUMPING EN LOS TRATADOS DE LIBRE COMERCIO FIRMADOS Y RATIFICADOS POR COLOMBIA}

Partimos del principio general según el cual los mercados internacionales en sus relaciones comerciales deben abrir la puerta a la posibilidad de adelantar un proceso de competencia capaz de asignar los recursos de manera eficaz en búsqueda del bienestar y el desarrollo para las economías locales.

Es así como la transparencia y la cooperación juegan un papel fundamental dentro de estas relaciones comerciales bilaterales a nivel internacional, ya que este es un compromiso que las partes deben asumir para lograr el objetivo trazado, que conduce a una política de fortalecimiento del mercado, que evita el trato discriminatorio e impide conductas que pongan en peligro la sana competencia entre las partes que conforman el Acuerdo.

Es por esto que dentro de los varios mecanismos de los que se pueden valer los Estados para fortalecer su posición en los mercados internacionales y lograr un mayor crecimiento así como estabilidad en sus economías, están los Tratados de carácter bilateral y dentro de ellos los Acuerdos por los que se establecen zonas de libre comercio.

El marco establecido por Colombia en los diferentes TLC respecto del Dumping se encuentra en la regulación de la OMC y el Acuerdo Antidumping del GATT de 1994, cuyo fin, según lo hemos señalado es lograr que los Estados Parte limiten el desarrollo de prácticas anticompetitivas y desleales dentro de los mercados nacionales o dentro de la zona de libre comercio, en búsqueda de promover que las economías internas y la producción nacional evolucione pero también se fortalezca competitivamente dentro del mercado internacional.

No se puede olvidar que las finalidades y los intereses de cada nación respecto de las políticas de competencia son distintos, lo que por supuesto marca orientaciones legislativas y medidas proteccionistas que en ciertos casos pueden oponerse a los fines mismos de la integración económica.

A la anterior divergencia se suman las problemáticas fundamentales de la protección de la competencia cuando ésta se inserta en un contexto de relaciones internacionales y que IBARRA PARDO señala son las siguientes: (1) La apertura económica trae consigo no solo una mayor competencia sino que además una variedad de elementos nuevos que la deterioran, (2) El riesgo existente de que los efectos negativos se den también en los mercados de exportación, (3) Las expectativas del consumidor respecto de la ganancia que trae consigo la liberación de los mercados dentro de los procesos de globalización ${ }^{25}$. 
Frente al primer punto es necesario establecer mecanismos que conduzcan a eliminar el abuso de la posición de dominio que restringe la competencia e impide el libre ejercicio de la misma dentro del mercado internacional, sin olvidar que, en ocasiones la mayoría de estas prácticas vienen respaldadas por el Gobierno de la parte exportadora. Respecto de la segunda, se establece que estas conductas se producen por la imposición de obstáculos que impiden el acceso al mercado de exportación como por ejemplo la existencia de actos proteccionistas, de políticas de carteles o de monopolización de los canales de distribución, frente a los cuales es necesario establecer una política regulatoria de tales conductas. Y, frente al tercer punto, es necesario cerciorarse que estas ventajas no sean disminuidas o eliminadas por Acuerdos producidos entre productores nacionales y extranjeros, que conlleven a la anulación de la libre competencia y a mayores atentados contra los consumidores. ${ }^{26}$

Una problemática adicional se encuentra frente a los competidores, tanto nacionales como extranjeros a los que las relaciones comerciales entre ambos países los podría afectar de forma desigual, debeido al mayor desarrollo productivo y tecnológico que tienen los demás países respecto deColombia.

Las anteriores problemáticas deben ser enfrentadas por Colombia en el desarrollo de las relaciones comerciales que se adelanten con otros países en virtud del TLC y como bien lo señala IBÁÑEZ PARRA, para esto se requiere de unas estrategias de cooperación entre ambas partes pero además, políticas que les permitan superar los obstáculos existentes ${ }^{27}$.

IBÁÑ̃EZ PARRA nos recuerda que adicionalmente el mercado cuenta con otra clase de barreras de acceso al mercado, denominadas "Barreras Naturales" estas son aquellas que aun cuando no existan conductas anticompetitivas se encuentran presentes en cualquier mercado en la medida en que son connaturales al mismo. Estas barreras naturales son los costos de transporte o de publicidad, los gastos de intermediación, los costos de comercialización, las economías a escala y la cultura del consumidor. Estos obstáculos solo pueden superados por los mismos competidores colombianos y dada su importancia no pueden ser ignorados desde ningún punto de vista por las políticas de protección a la competencia. ${ }^{28}$

Estado Unidos (2005), consultado el 19 de Mayo de 2012, en: http://www.usergioarboleda. edu.co/civilizar/revista9/MODELO_COMPETENCIA_PRACTICABLE_TLC ENTRE_ COLOMBIA ESTADOS UNIDOS.pdf), p. 10. 


\subsection{Tratados de Libre Comercio firmados por Colombia}

A continuación pasamos a realizar un análisis del marco regulatorio respecto de la política antidumping incorporada en los TLC firmados y ratificados por Colombia con Canadá, Corea del Sur y, especialmente, en el Acuerdo suscrito con los con Estados Unidos de Norteamérica.

\subsubsection{Acuerdo de Libre Comercio entre Colombia y Canadá}

El TLC firmado entre Colombia y Canadá el 21 de noviembre de 2008 en la ciudad de Lima y cuyo canje de notas se realizó el 18 y 20 de febrero del año 2010, fue aprobado mediante la Ley 1363 del 9 de diciembre de 2009 y pasó el filtro de constitucionalidad el día 24 de julio de 2010 conforme lo señala la sentencia C - 608 del 3 de agosto de 2010 de la Corte Constitucional con ponencia del Dr. Humberto Sierra Porto. De igual manera este Acuerdo bilateral fue aprobado en Canadá el 21 de junio de 2010 y, finalmente, entró en vigencia el 15 de Agosto de 2011.

La regulación establecida en materia de política antidumping se encuentra incorporada en el capítulo 7 y se denomina "Medidas de Salvaguardia y Defensa Comercial".

En primer lugar, se debe señalar que la sección A denominada "Medidas de Salvaguardia ${ }^{29 "}$ establece que los Estados Parte se obligan a respetar los derechos y obligaciones incorporados en el artículo XIX del GATT de 1994 y el Acuerdo sobre Salvaguardia. Adicionalmente, se confiere el derecho de excluir las importaciones de una mercancía originaria cuando la otra Parte imponga una medida de salvaguardia global, siempre que la autoridad competente ${ }^{30}$ adelante el proceso de investigación de acuerdo con lo establecido en el capítulo 7, sección A, artículo 705 denominado "Procedimientos de Investigación y Requisitos de Transparencia", que lleve a concluir que tales importaciones no constituyen una

29 "Las medidas de salvaguardia se definen como medidas "de urgencia" con respecto al aumento de las importaciones de determinados productos cuando esas importaciones bayan causado o amenacen causar un daño grave a la rama de producción nacional del Miembro importador (artículo 2). Esas medidas, que en general adoptan la forma de suspensión de concesiones u obligaciones, pueden consistir en restricciones cuantitativas de las importaciones o aumentos de los derechos por encima de los tipos consolidados". ORGANIZACIÓN MUNDIAL DEL COMERCIO. La Ronda de Doba, consultado el 23 de Julio de 2013, en: http://www.wto.org/spanish/tratop_s/safeg_s/safeg_info_s.htm.

30 Autoridad investigadora competente: "(a) en el caso de Canadá, Canadian International Trade Tribunal, o su sucesor; $y$ (b) en el caso de Colombia, la Subdirección de Prácticas Comerciales del Ministerio de Comercio, Industria y Turismo, o su sucesor," ACUERDO DE LIBRE COMERCIO ENTRE LA REPÚBLICA DE COLOMBIA Y CANADÁ, Capítulo 7, Artículo 707, Inciso 3. 
causa sustancial de daño grave ${ }^{31} \mathrm{o}$ amenaza del mismo $^{32}$, tal como lo señala el artículo 701 inciso 2 del Tratado.

2. Este Acuerdo no confiere derechos u obligaciones adicionales a las Partes respecto a las medidas tomadas en virtud del Artículo XIX del GATT de 1994 y el Acuerdo sobre Salvaguardias, excepto que la Parte que imponga una medida de salvaguardia global podrá excluir las importaciones de una mercancía originaria de la otra Parte, si la autoridad investigadora competente de dicha Parte concluye que tales importaciones no constituyen una causa sustancial de daño grave $o$ amenaza del mismo.

En segundo lugar, el Tratado prohíbe que alguna de las partes conserve sobre una misma mercancía o producto y durante un mismo periodo de tiempo una medida de salvaguardia o una media proveniente del artículo XIX del GATT de 1994 y el Acuerdo sobre Salvaguardias. Respecto de esto, el capítulo 7, sección A, artículo 702 establece que las medidas solo podrán imponerse en dos casos: En primer lugar, cuando se busque evitar o remediar la producción de un daño grave $y$, en segundo lugar, para detener la posible reducción o aumento de una tasa arancelaria sobre una mercancía, de conformidad con lo establecido en este Acuerdo comercial y con el cumplimiento de los dos requisitos establecidos en el inciso primero del artículo 702, esto es, que la medida de salvaguardia se aplique durante un solo periodo de transición y que la disminución o eliminación de la tasa arancelaria conlleve a que el aumentosde las cantidades de importación de una mercancía originaria traigan consigo un daño o una amenaza grave de éste producción nacional.

\section{"Artículo 702: Imposición de una Medida de Salvaguardia}

1. Una Parte podrá aplicar una medida de salvaguardia descrita en el párrafo 2:

(a) sólo durante el período de transición, y

(b) si como resultado de la reducción o eliminación de un arancel aduanero en virtud de este Acuerdo, una mercancía originaria sea importada en el territorio de la Parte, en cantidades que hayan aumentado en tal monto en términos absolutos o relativos a la producción nacional y en condiciones tales que constituyan una causa sustancial de daño grave, o una amenaza a una industria nacional que produzca una mercancía similar o directamente competidora".

31 El término daño grave: "significa un deterioro general significativo de una industria nacional," ACUERDO DE LIBRE COMERCIO ENTRE LA REPÚBLICA DE COLOMBIA Y CANADÁ, Capítulo 7, Artículo 707, Inciso 3.

32 El término amenaza de daño grave: "significa un daño grave que, basado en bechos y no simplemente en alegaciones, conjeturas o posibilidades remotas, es a todas luces inminente," ACUERDO DE LIBRE COMERCIO ENTRE LA REPÚBLICA DE COLOMBIA Y CANADÁ, Capítulo 7, Artículo 707 , Inciso 2. 
En tercer lugar, se hace necesario resaltar que el capítulo 7, sección A, artículo 704 del Acuerdo Comercial establece las disposiciones normativas que se deben seguir en las medidas de salvaguardia, para lo cual señala que las partes no pueden mantenerlas por un período de tiempo que supere los 3 años ni tampoco cuando se termine el período de transición. Adicionalmente, establece que las partes podrán hacer uso de estas medias solo una vez sobre una misma mercancía que tenga su origen en el territorio de producción de la otra Parte.

Respecto de la finalización del uso de las medidas de salvaguardia, el Acuerdo Comercial impone que la tasa arancelaria será la que haya sido acordada por las Partes y se prevé que cuando una Parte aplique una de estas medidas por un período de tiempo superior a un año, deberá liberarla progresivamente y de forma regular.

Por último, el país que haga uso de las medidas de salvaguardia deberá pagar a la Parte exportadora una compensación de liberalización comercial que será acordada entre las Partes, pero si no se llega a un Acuerdo, la Parte a la que se le impuso la medida tiene la potestad de aplicar durante el período de tiempo necesario las medias arancelarias que le permitan obtener los efectos comerciales equivalentes que sobrevendrían por la imposición de una medida de salvaguardia.

En la sección B se regulan las "Medidas antidumping y Compensatorias" en donde se establece que las partes se obligan a respetar los derechos y las obligaciones adquiridas con la OMC, entidad a quien, además, se le asigna la potestad exclusiva de aplicar las medidas antidumping y las medidas compensatorias.

\subsubsection{Acuerdo de Libre Comercio entre Colombia y la República de Corea}

Las negociaciones entre los Estados Parte que llevaron a la firma de este Tratado Comercial comenzaron en Seúl en el año 2009 y terminaron con la firma de sus respectivos representantes, los Ministros de Comercio Bark Taebo y Sergio Díaz-Granados el 21 de febrero del año 2013 en esta misma ciudad. Este Acuerdo comercial deberá ser puesto a disposición de los respectivos organismos parlamentarios para su análisis y posterior aprobación constitucional, lo cual no obsta para analizar la regulación establecida sobre la política de protección de la competencia y prácticas Dumping, ubicadas en el capítulo 7 denominado "Defensa Comercial" dividido en dos secciones: la sección A que contempla los Acuerdos sobre las "Medidas De Salvaguardia" y la sección B que establece toda la reglamentación sobre "Medidas antidumping y Compensatorias".

Sobre las "Medidas De Salvaguardia" se debe resaltar que su uso otorga el derecho de aumentar o reducir la tasa arancelaria pactada por la Parte que ve afectadas las importaciones de mercancía de origen sobre las cuales recaen 
dichas medidas cuando éstas generan un daño ${ }^{33}$ o una amenaza grave ${ }^{34}$ para la industria doméstica que produce un bien similar, tal como lo regla el capítulo 7, sección $\mathrm{A}$, artículo 7.1 .

\section{"Artículo 7.1: Aplicación De Una Medida De Salvaguardia}

Si como resultado de la reducción o eliminación de un derecho de aduanas en virtud del presente Acuerdo, un producto originario de una Parte está siendo importado en el territorio de la otra Parte en cantidades cada vez mayores, en términos absolutos o relativos a la producción doméstica, y en condiciones en que las importaciones de tales productos originarios de la otra Parte constituyen una causa sustancial de daño grave o amenaza del mismo, a una industria doméstica que produce un bien similar o directamente competidor, la Parte podrá:

(a) suspender la reducción adicional de la tasa de derecho de aduana sobre el producto prevista en el presente Acuerdo; o

(b) aumentar la tasa de derecho de aduana sobre el producto a un nivel que no exceda el menor de:

(i) el arancel NMF en vigor aplicado al producto en el momento en que se adopte la medida; $\mathrm{y}$

(ii) el arancel base especificado en la Lista del Anexo 2.A (Eliminación de Aranceles Aduaneros)".

En segundo lugar, las normas que regulan la aplicación de las medidas de salvaguardia se encuentran establecidas en capítulo 7, sección $A$, artículo 7.2 que se denomina "Normas para una medida de salvaguardia".

En virtud de ésta normatividad se impone a las Partes la obligación de que las autoridades competentes ${ }^{35}$ en un término máximo de un año adelanten una investigación dirigida a obtener la información que permita conocer la existencia de estas prácticas en las relaciones comerciales que se adelanten entre los Estados Parte de este Acuerdo.

33 El término daño grave: "significa un menoscabo general significativo de la situación de una industria nacional,". ACUERDO DE LIBRE COMERCIO ENTRE LA REPÚBLICA DE COLOMBIA Y LA REPÚBLICA DE COREA, Capítulo 7, Artículo 7.6, Inciso 4.

34 El término amenaza de daño grave: "significa un daño grave que, basado en los bechos y no meramente en alegatos, conjeturas o posibilidades remotas, es claramente inminente $; "$ ACUERDO DE LIBRE COMERCIO ENTRE LA REPÚBLICA DE COLOMBIA Y LA REPÚBLICA DE COREA, Capítulo 7, Artículo 7.6, Inciso 1.

35 El término autoridad investigadora significa: "(a) para Colombia, el Ministerio de Comercio, Industria y Turismo, o su sucesor; y (b) para Corea, La Comisión de Comercio de Corea (Korea Trade Comission) o su sucesor". ACUERDO DE LIBRE COMERCIO ENTRE LA REPÚBLICA DE COLOMBIA Y LA REPÚbliCA DE COREA, Capítulo 7, Artículo 7.6, Inciso 2. 
En tercer lugar, se observa que el convenio establece una serie de prohibiciones para las Partes intervinientes ya que no permite la aplicación de esta clase de medidas salvo que sean necesarias para evitar o reparar la producción de un daño grave y para facilitar el ajuste por un período de tiempo limitado, el cual no podrá ser superior a los dos años salvo que las autoridades determinen que es viable prorrogarlo por un año más de conformidad con los lineamientos establecidos en este Acuerdo, sin posibilidad de que tal prórroga pueda superar los tres años.

Adicionalmente, se prohíbe que las Partes apliquen estas medidas cuando se ha vencido el período de transición. Tampoco permite que las medidas de salvaguardia sean empleadas más de una vez sobre el mismo producto y adiciona que en caso de que la aplicación de estas medidas tenga un período de duración superior a un año, la Parte que la aplica tendrá que liberarla progresivamente durante el tiempo de aplicación.

En cuarto lugar, este Acuerdo regula la posibilidad de aplicar unas "Medidas de Salvaguardia Provisionales" que buscan enfrentar los casos en donde hay una situación de emergencia en los que la demora en la investigación puede generar un daño irreparable a la industria nacional. Para la aplicación de dichas medidas se ha implementado todo un procedimiento que comienza con la publicación de la solicitud y que otorga a la contra parte un plazo mínimo de 20 días para la presentación de las pruebas y opiniones que considere pertinentes. Adicionalmente se establece que las autoridades competentes deberán realizar un análisis previo y completo sobre la existencia de prácticas que dañen o amenacen con causar un daño grave la industria nacional.

De éstas medidas no se podrá hacer uso por un período de tiempo inferior a 45 días contados a partir del inicio de la investigación, se prohíbe que superen los 200 días y se impone la obligación de reembolso de los aumentos que se produzcan sobre los aranceles cuando la investigación anteriormente mencionada llegue a la conclusión de que no existe tal situación de urgencia.

En quinto lugar, se establece que una vez es aplicada la medida de salvaguarda surge para el Estado la obligación de pagar, en un plazo máximo de 30 días, una compensación a la parte perjudicada con la medida, que busca que "en la liberalización comercial se alcancen los mismos efectos comerciales producidos en el valor de los aranceles adicionales aplicados con el uso de esta medida" ${ }^{\prime \prime 6}$.

Esta compensación deberá ser pactada de manera bilateral por ambas partes para lo cual cuentan con un plazo máximo de 30 días y en caso de no llegar a un Acuerdo el convenio establece que la parte contra cuyo producto se haya aplicado la media tendrá la potestad de ejercer el derecho de suspensión sobre "la aplicación de las concesiones sustancialmente equivalentes con respecto a los 
productos originarios de la Parte que aplica la medida de salvaguardia". ${ }^{37}$ Este derecho de suspensión no podrá ser ejercido dentro de los primeros 2 años en que se encuentre vigente la aplicación de una medida de salvaguardia, siempre que dicha medida haya sido "adoptada como resultado de un aumento en términos absolutos de las importaciones y de que tal medida esté conforme a disposiciones del presente Acuerdo"s.

En sexto lugar, el capítulo 7, sección A, artículo 7.5 del Tratado regula lo que denomina "Medidas de Salvaguardia Global" que atiende a las obligaciones y los derechos que se encuentran incorporados por el artículo XIX del GATT de 1994 y el Acuerdo sobre Salvaguardias que conservan las partes vinculadas en virtud de este Tratado bilateral. A lo cual adiciona la posibilidad de que una Parte excluya las importaciones de mercancía de origen de la otra Parte cuando en la aplicación de una de estas medidas se cause un daño o una amenaza grave a la producción nacional.

Para finalizar se prohíbe que las Partes empleen al mismo tiempo y sobre el mismo producto una medida de salvaguardia global regulada por el artículo XIX del GATT de 1994 y una medida de salvaguardia de las previstas en el Tratado.

Por otro lado se observa que la regulación de las políticas antidumping se encuentra ubicada en la sección B del capítulo 7 denominado "Medidas antidumping y Compensatorias", que como primera medida establece que las Partes del presente Acuerdo comercial se someten a las obligaciones y los derechos adquiridos en el artículo VI del GATT de 1994, el Acuerdo Antidumping y el Acuerdo de la OMC.

En este punto es de vital importancia resaltar el interés de las partes en incorporar una política de competencia transparente, edificada sobre los principios del Acuerdo de la $\mathrm{OMC}$, por lo que dispone que los márgenes de antidumping deberán establecerse y evaluarse de conformidad con lo que regla el Acuerdo Antidumping ya mencionado. Adicionalmente instituye que cuando una parte ejerza un derecho antidumping surge para ésta la obligación de aplicar el "derecho inferior", que consiste en la imposición de un derecho menor al margen de Dumping ${ }^{39}$ cuando éste derecho sea el necesario y adecuado para eliminar el daño que se ha causado en la industria nacional.

Finalmente, se regula todo el procedimiento de notificaciones y consultas en la aplicación de medidas antidumping, para lo cual en primer lugar se señala

Ibídem. Inciso 2.

Ibídem. Inciso 3

El término margen de Dumping está definido en el párrafo 2 del artículo VI del GATT "como la diferencia entre el valor normal y el precio de exportación y establece el vínculo entre el Dumping y el margen Dumping El margen Dumping refleja la magnitud del Dumping y es uno de los factores ban de tenerse en cuenta para determinar si el Dumping causa o amenaza causar una daño importante, en virtud del artículo 3.4 del Acuerdo Antidumping. El margen Dumping se define en relación con el producto". CONDON J. Bradly. El Derecho de La Organización Mundial del Comercio, Tratados, Jurisprudencia y práctica (2007), Cameron May ltd., Reino Unido., p. 420. 
que antes de iniciar la respectiva investigación por parte de las autoridades competentes, la parte interesada deberá realizar una notificación por escrito a la otra parte con el fin de que esta sea informada de la situación y tenga la oportunidad de pronunciarse al respecto. Si la parte interesada adopta unas medidas previas al inicio de la investigación para hacer frente a las prácticas de Dumping y los daños causados por las mismas, ésta tendrá la obligación de conferirle a la otra parte la oportunidad de realizar las consultas respecto de las medidas adoptadas que podrían dar lugar a la suspensión del proceso de investigación.

En segundo lugar se establece que la parte que recibe la solicitud deberá informar por escrito a la otra parte sobre dicha recepción con el fin de otorgar el especio adecuado para adelantar las consultas y las reuniones que fueren necesarias respecto de la aplicación de la medida antidumping.

\subsubsection{Acuerdo de Libre Comercio entre Colombia y los Estados Unidos de América}

\subsubsection{Antecedentes}

Las negociaciones para la suscripción del TLC iniciaron el 30 de abril de 2003 cuando el ex presidente Álvaro Uribe Vélez le propuso la suscripción del tratado comercial al presidente de los Estados Unidos de la época George W. Bush, quien por medio del responsable de la oficina comercial, el señor Robert Zoellick, contestó afirmativamente, respuesta que incluía la negociación del tratado con Perú y Ecuador los cuales junto con Colombia hacían parte del ATPDEA $^{40}$, dejando por fuera a Bolivia y Venezuela ${ }^{41}$.

Es así como 18 de mayo de 2004 en el Centro de Convenciones de Cartagena de Indias se dio inicio a las negociaciones para el TLC que se llevaría a cabo entre Estados Unidos y Colombia, Perú y Ecuador. ${ }^{42}$

Estas negociaciones encontraron fuertes críticas por parte de la Iglesia Católica, las ONG, los académicos, el sector agropecuario y el gremio de las farmacéuticas nacionales, al considerar el TLC como un enemigo de la eco-

40 "La Ley de Preferencias Arancelarias Andinas (ATPA, por sus siglas en inglés) es un régimen de excepción otorgado unilateralmente por los Estados Unidos al Perú, Bolivia, Colombia y Ecuador para apoyar la lucha contra el tráfico ilícito de drogas." LEY DE PROMOCION COMERCIAL ANDINA Y ERRADICACION DE LA DROGA (ATPDEA). Ministerio de Comercio Exterior y Turismo del Perú, consultado el 17 de Agosto de 2012. en: http://www.mincetur.gob.pe/comercio/ Otros/Atpa/atpa.htm.

41 Correa C. Jorge. Portafolio.co., Historia de un proceso que tardó 7 años, consultado el 17 de Agosto de 2012, en Internet: http://www.portafolio.co/negocios/historia-un-proceso-quetardo-7-anos.

42 Ibídem. 
nomía colombiana por la difícil competencia con la que se enfrentarían las empresas nacionales frente a un mercado estadounidense maduro y exigente ${ }^{43}$.

En abril de 2005 cuando se realizaba la novena ronda de negociaciones, Ecuador quedó por fuera de este proceso gracias a una revuelta que produjo el cambio de presidente en este país. De igual forma en diciembre de éste mismo año Perú dio por terminadas las negociaciones. ${ }^{44}$

Las negociaciones con Colombia después de un largo proceso, finalizaron en la ciudad de Washington el 27 de febrero del 2006, pero el Acuerdo se congeló producto del veto impuesto por los demócratas, quienes se fundaron en los pocos avances que había en Colombia en materia de derechos humanos y derechos laborales. Con la llegada de Juan Manuel Santos a la presidencia de Colombia y la de Barack Obama a la Estados Unidos se dio inicio a un "Plan de Acción" que buscaba el descongelamiento del Acuerdo comercial. ${ }^{45}$

Es así como, hasta el 22 de noviembre del 2006 en la ciudad de Washington se suscribió el TLC entre Colombia y Estados Unidos, aprobado por el Congreso de la República de Colombia en junio de 2007 y un mes después sancionado por el Presidente mediante la Ley 1143 de 2007.46

Respecto al Acuerdo se pronunció la Corte Constitucional colombiana a través de la sentencia C-750 de Julio de 2008 con ponencia de la Dra. Clara Inés Vargas Hernández encontrando que la Ley 1143 de 2007 se encontraba conforme a la Constitución Nacional de 1991. El 21 de noviembre de 2007 se firmó por medio de la Ley 1166 el "Protocolo Modificatorio del Acuerdo Comercial entre Colombia y Estados Unidos", cuya exequibilidad fue declarada por la Corte Constitucional en sentencia C-751 de 2008 con ponencia del Dr. Manuel José Cepeda Espinosa.

Finalmente, en octubre de 2011 después de la aquiescencia del Congreso Estadounidense se comenzó con la implementación del TLC ${ }^{47}$, que entró en vigencia el 15 de mayo de 2012, atendiendo a lo establecido por el presidente Juan Manuel Santos y el presidente Barack Obama el 15 de abril de 2012, fecha en la cual se realizó el canje de notas correspondiente. ${ }^{48}$

Ibídem

Ibídem

REDACCIÓN DE EL PAÍS. El País.com.co., El TLC, una aventura que partirá la bistoria de Colombia en dos, consultado el 17 de Agosto de 2012, en: http://www.elpais.com.co/elpais/economia/ noticias/tlc-aventura-cambiara-colombianos.

6 EL TIEMPO. Tratado de Libre Comercio entre Colombia y Estados Unidos, EL TIEMPO No. 1, (2012).

Ibídem.

EL TIEMPO. Tratado de Libre Comercio entre Colombia y Estados Unidos, EL TIEMPO No. 1, (2012). 


\subsubsection{Política de protección a la competencia}

El TLC entre Colombia y Estados Unidos incorpora la política de protección a la competencia en el capítulo trece titulado "Política de Competencia, Monopolios Designados y empresas del Estado"; lo primero que cabe destacar en torno al tema, es el interés de las Partes en proscribir claramente aquellas conductas que puedan restringir el comercio o la inversión recíproca, tal y como lo dispone el capítulo 13, artículo 13.1 referente a los objetivos de dicho capitulo, así:

\section{"Artículo 13.1: Objetivos}

Reconociendo que la conducta sujeta a este Capítulo tiene el potencial de restringir el comercio e inversión bilateral, las Partes consideran que proscribir dicha conducta, implementar políticas de competencia económicamente consistentes y cooperar en materias cubiertas por este Capítulo, ayudarán a asegurar los beneficios de este Acuerdo".

Con el propósito de lograr el objetivo anteriormente expuesto, las Partes se comprometieron en el marco del TLC a crear o mantener la legislación existente sobre protección a la competencia, las autoridades en la materia e igualmente se obligaron a establecer las acciones necesarias para eliminar las prácticas que lesionen la competencia y la eficiencia económica de los mercados.

De lo anterior, puede concluirse que el fin básico planteado por este Acuerdo consiste en implementar una zona libre de aranceles en la cual cada Parte se obliga a incorporar una política de protección a la competencia y de ésta forma logra mantener su autonomía en la materia. ${ }^{49}$

La política de competencia se asienta sobre los principios generales de la libre y leal competencia, de la igualdad y de la no discriminación por la nacionalidad de quienes llegasen a ser objeto de los procedimientos adelantados por las autoridades nacionales. Adicionalmente ambas partes se comprometen a garantizar el debido proceso antes de llegar a imponer cualquier medida sancionatoria.

Esta política de restricción a las prácticas que atentan contra la libre competencia de los mercados se basa en la cooperación de las partes para la aplicación de la legislación de la libre competencia, como lo menciona el art. 13.4 denominado "Grupo de Trabajo".

Además se observa que los aranceles que se aplican a las materias primas y a los bienes de capital en Colombia son superiores frente a los que se aplican en Estados Unidos, lo cual conduce a que se compita en condiciones inequitativas y a que se generen desventajas para los productores colombianos. BARBOSA MARIÑO J. y LOZANO ORTIZ DE ZÁRATE M., ¿Cómo leer el tratado de libre comercio Colombia-Estados Unidos de América?, resultados preliminares de la línea de investigación tratado de libre comercio, Colombia-estados unidos (2008), consultado el 18 de Agosto de 2012, en: http://www.javeriana.edu.co/juridicas/pub rev/ documents/7BarbosayLozano_001.pdf. p. 8 . 
"Artículo 13.4: Grupo de Trabajo

Las Partes establecerán un grupo de trabajo integrado por representantes de cada Parte. El grupo de trabajo procurará promover el mayor entendimiento, comunicación y cooperación entre las Partes en relación con las materias cubiertas por este Capítulo. El grupo de trabajo informará sobre el estado de sus esfuerzos a la Comisión dentro de los tres años siguientes a la entrada en vigor de este Acuerdo, y podrá bacer recomendaciones apropiadas para acciones futuras que puedan continuar promoviendo el logro de los objetivos de este Artículo".

Atendiendo a lo anterior se puede observar que este Acuerdo Comercial cuenta con las siguientes tres características ${ }^{50}$ :

a. Establece conceptos que requieren de un nivel de conocimiento profundo en la materia ya que han sido incorporados por la evolución del derecho del comercio internacional y que imprimen un nivel de exigencia mayor para su comprensión, un ejemplo es el concepto de la cláusula de la nación más favorecida que ha sido desarrollado por el GATT de 1947 y por la Organización Mundial del Comercio ${ }^{51}$.

b. Es necesario interpretar cada uno de los artículos que lo conforman; el ejemplo que se plantea es el de cómo implementar el libre ejercicio de la competencia dentro de las relaciones comerciales que se desarrollen entre Colombia y Estado Unidos?, establecida el capítulo trece, en el capítulo ocho, en el de contratación pública, inversión, comercio transfronterizo de servicios, servicios financieros, telecomunicaciones y el anexo I del TLC ${ }^{52}$.

El TLC debe ser interpretado desde dos niveles diferentes ya que se aplica a dos ordenamientos jurídicos distintos, lo que hace necesario examinar si las obligaciones allí planteadas cuentan, por un lado con suficiente especificidad para su entendimiento y, por otro, si son tan generales que dan paso a su aplicación en ambos sistemas jurídicos ${ }^{53}$.

IBÁÑEZ PARRA señala que el mayor obstáculo que existe para ingresar a los mercados estadounidenses no son las barreras arancelarias sino los subsidios, las ayudas estatales, las cuotas de importación y las medidas antidumping, es decir lo que se denomina "Barreras no arancelarias" que vienen a formar parte del "Nuevo proteccionismo" ${ }_{54}$, lo cual explica la prohibición impuesta a los negociadores estadounidenses de incluir Acuerdos en el TLC que disminuyan la eficacia de la política comercial sobre la competencia y las medidas antidumping establecidas en dicho país. ${ }^{55}$ Estado Unidos (2005), consultado el 19 de Mayo de 2012, en: http://www.usergioarboleda. 
Lo que se busca dentro de una política de comercio internacional proteccionista y antimonopólica es mejorar la competitividad de los mercados internos, pero este objetivo puede variar dependiendo del país de que se trate, si este es importador o exportador y si la normatividad interna de cada país sobre la protección a la competencia tiene el carácter de instrumento o si es considerada como un fin en sí misma ${ }^{56}$. Solo a manera de ejemplo debe tenerse en cuenta que mientras para Estados Unidos de América la competencia es considerada como un fin en sí misma y su política está dirigida al crecimiento de la eficacia económica, en la Unión Europea en donde se le asigna un carácter puramente instrumental al verla como el medio para lograr sus objetivos de integración. ${ }^{57}$

Pero el problema principal radica en que estas políticas comerciales de protección a la competencia se han dejado plasmadas en el TLC con un amplio margen de discrecionalidad y esto le imprime un alto grado de inseguridad jurídica a las relaciones comerciales que se van a dar entre ambas partes. Esto ocurre porque ${ }^{58}$ :

i. Estas políticas no pueden ser negociadas, ya que, como lo mencionábamos anteriormente Estados Unidos ha excluido expresamente las negociaciones frente a esta materia $y$,

ii. Se encuentra autorizado por el artículo XXIV del GATT.

A priori podemos afirmar que los principios que rigen la política de competencia en el marco del TLC se encuentran conformes con los principios que dentro del ordenamiento Colombiano rigen el tema, esto es, el principio de la libre iniciativa privada, el de la libertad de empresa y el de la libre competencia.

El Acuerdo del TLC impone una política de protección y promoción de la competencia que incluye varios aspectos a saber:

- La regulación de los monopolios.

- Las empresas del Estado.

- Las medidas para enfrentar los casos donde la liberación de las barreras arancelarias produce un alto nivel de importaciones que pudiese llegar a afectar un sector de la producción nacional y las medidas antidumping.

- Las medidas antidumping y derechos compensatorios.

- Procedimientos

A continuación pasamos a exponer cada uno de ellos:

edu.co/civilizar/revista9/MODELO COMPETENCIA PRACTICABLE TLC ENTRE COLOMBIA_ESTADOS_UNIDOS.pdf

57 Vid. NEALE,A.D. y GOYDER, D.G. The Antitrust Laws of the U.S.A. University Press, Cambridge, Third Edition, pág. 20-21. (Como se cita en IBÁÑEZ PARRA Oscar. El modelo de competencia económica practicable del TLC entre Colombia y Estado Unidos (2005), consultado el 19 de Mayo de 2012, en: http://www.usergioarboleda.edu.co/civilizar/revista9/MODELO COMPETENCIA_PRACTICABLE_TLC_ENTRE_COLOMBIA_ESTADOS_UNIDOS. pdf)

Ibídem. 


\subsubsection{La regulación de los monopolios}

El TLC establece que los monopolios no están prohibidos pero señala que estos pueden crear obstáculos para el mercado, por lo que los Estados Parte del Acuerdo se comprometen a garantizar cuatro puntos fundamentales:

a. Que los monopolios no actuarán de manera incompatible con las obligaciones asumidas mediante este Acuerdo.

b. Que los monopolios actuarán comercialmente, únicamente en los mercados relevantes.

c. Que estos monopolios no podrán dar un trato discriminatorio con la otra parte en las relaciones comerciales establecidas.

d. No podrá valerse de su posición monopolística para incurrir en prácticas anticompetitivas, cualquiera sea el escenario que se presente.

Finalmente el numeral tercero del artículo trece punto cinco 13.5 del capítulo trece establece que todo lo que se encuentra definido respecto de los monopolios no será aplicado en materia de contratación pública y la razón está en que el interés de los estados se dirige a facilitar el acceso al comercio sin ninguna limitación y por esto se incluyó un capítulo independiente que aborda integralmente el tema y permite que el Estado intervenga libremente en búsqueda de la satisfacción de sus propias necesidades y la de los ciudadanos.

Ahora bien, atendiendo a lo anteriormente expuesto, en este punto podemos concluir que la regulación contenida en el TLC resulta compatible con la normatividad constitucional colombiana dado que se observa como el artículo 333 establece que la actividad económica y la iniciativa privada son libertades que pueden ser ejercidas dentro de los límites del respeto al bien común y que es el Estado el encargado de impedir el ejercicio de usos o prácticas abusivas y es así como en desarrollo de éste mandato constitucional encontramos, entre otras normas, el artículo 50 del Decreto 2153 de 1992 y la ley 155 de 1959 que prohíben el abuso y no la posición de dominio per se, es decir, establecen que las empresas pueden ser tan grandes como su eficiencia se los permita, siempre y cuando no desarrollen conductas de abuso frente a sus competidores $\mathrm{y}$ frente al consumidor.

En éste punto encontramos pronunciamientos jurisprudenciales en donde se confirma el argumento anteriormente expuesto, en el sentido de que se concluye que la censura radica es en el abuso de la posición de dominio que ostenta una empresa dentro del mercado por considerarlo una práctica que atenta contra las normas que propenden por el libre acceso al comercio. Es así como se observa como en sentencia del veintitrés (23) de junio de 1993 T-241 con ponencia del Dr. EDUARDO CIFUENTES MUÑOZ la Corte Constitucional expone:

"La Constitución ba elevado la libre competencia a principio rector de la actividad económica, en beneficio de los consumidores y de la misma libertad de empresa. Es del resorte de la ley probibir - 
excepcionalmente autorizar bajo ciertos supuestos y condiciones - conductas, Acuerdos o prácticas que tenga por efecto impedir, restringir, obstaculizar ofalsear la libre competencia en cualquier mercado de bienes o de servicios, tarea ésta del legislador esencial para conformar y mantener mercados eficientes y para que en verdad la libre competencia pueda ser "un derecho de todos", como lo consagra la Constitución (CP art. 333). De otra parte, la ley debe impedir que personas o empresas que detenten una posición dominante en el mercado la exploten de manera abusiva. La posición dominante de una empresa suele definirse como la posibilidad de ejercer un comportamiento independiente respecto de los precios, condiciones de venta, volúmenes de producción y sistemas de distribución de bienes o de servicios dado el control que ella puede ejercer sobre una parte significativa del mercado en razón de la magnitud de sus recursos financieros, tecnológicos o del manejo estratégico de las materias primas y demás factores económicos. El abuso de la posición dominante - no estrictamente ésta - es la que resulta censurable. Simplemente para efectos ilustrativos y dado que el Constituyente lo tuvo en mente, conviene citar el artículo 86 del Tratado de Roma constitutivo de la Comunidad Económica Europea que precisa algunas prácticas que se consideran abusivas de la posición dominante:

"(...) Tales prácticas podrán consistir, particularmente, en: a) imponer directa o indirectamente precios de compra, de venta u otras condiciones de transacción no equitativas; b) limitar la producción, el mercado o el desarrollo técnico en perjuicio de los consumidores; c) aplicar a terceros contratantes condiciones desiguales para prestaciones equivalentes, que ocasionen a éstos una desventaja competitiva, d) subordinar la celebración de contratos a la aceptación, por los otros contratantes, de prestaciones suplementarias que, por su naturaleza o según los usos mercantiles, no guarden relación alguna con el objeto de dichos contratos ${ }^{159}$.

Así mismo concluye la Corte Constitucional en sentencia No. T-375 de 1997 con ponencia del Dr. EDUARDO CIFUENTES MUÑNZ, que el ejercicio de una posición de dominio por sí misma no puede ser prohibida ni limitada dado que ésta es una práctica coherente con las leyes propias del mercado y en éste sentido solo será censurado el ejercicio abusivo de la misma, tal y como se expone a continuación:

"La posición dominante se refiere a un poder de mercado que le permite a un agente económico actuar con independencia de sus competidores, por lo menos dentro de un grado relativamente amplio y apreciable. El poder de mercado implica menos participación colectiva en la fijación de precios y cantidades $y$, correlativamente, mayor unilateralidad y relevancia de las decisiones que sobre estos extremos adopten las fuerzas dominantes que, de llegar a ser avasallantes, sustituyen los mecanismos de mercado. Las normas sobre competencia se enderezan a evitar concentraciones en los mercados $y$, desde este punto de vista, pueden proponerse evitar que se den posiciones dominantes. Sin embargo, cuando estas se presentan o cuando la ley las tolera, lo que puede obedecer a razones de eficiencia, lo que en modo alguno se puede permitir es que, además de este factor de pérdida de competitividad,

59 Para profundizar consulte: Acción de tutela instaurada por ASOCIACION DE PENSIONADOS DEL CAQUETA -ASOPENCA- contra CAJA DE PREVISION SOCIAL DEPARTAMENTAL DEL CAQUETA Y DEPARTAMENTO DEL CAQUETA. Sentencia T-241 del 23 de junio de 1993 de la Corte Constitucional, MP. EDUARDO CIFUENTES MUÑNOZ 
las personas o empresas en esa situación bagan un uso abusivo de su posición dominante o restrinjan y debiliten aún más el nivel de competencia existente (C.P. art., 333 )" 60.

2.1.3.4. ¿Cómo se regulan las Empresas del Estado?

Al igual que ocurre con los monopolios, el Acuerdo no impide la existencia o creación de una empresa del Estado, pero advierte que estas no deben obstaculizar la economía del libre mercado, y es por ello las Partes se comprometen a:

i. Comportarse de manera compatible con el Acuerdo.

ii. No brindar un trato discriminatorio en la venta a inversiones cubiertas.

En lo que respecta al cobro diferencial de precios en los mercados, las partes establecieron que siempre y cuando esta práctica se adelantara de conformidad con las condiciones comerciales normales ${ }^{61}$ no constituiría una actividad violatoria de la regulación establecida para los Monopolios designados y las empresas del Estado.

Adicionalmente el Acuerdo establece una forma para garantizar la transparencia en las políticas gubernamentales establecidas para la competencia, imponiendo que cualquiera de las partes podrá solicitar información sobre cumplimiento de las obligaciones asumidas, con las especificaciones que el mismo Acuerdo se encarga de señalar.

En este punto es importante resaltar que cuando el Estado ejerce su actividad comercial también está sujeto a los postulados señalados por la política de protección a la competencia y por lo tanto, no puede valerse de la posición prevalente que le otorga el derecho público para lograr ventajas económicas.

\subsubsection{La regulación antidumping}

En el capítulo ocho del TLC titulado "Defensa comercial", se expone toda la normatividad que regula la aplicación de las medidas establecidas para enfrentar los casos en donde la liberación de las barreras arancelarias llega a producir un nivel de importaciones tan alto que puede causar un daño significativo en un sector de la producción nacional. Adicionalmente este mismo capítulo

60 Para profundizar consulte: Acción de tutela instaurada por Marcelino Rodríguez Rojas contra Terpel Sur SA. - TERPEL Sentencia No. T-375 de 1997 de la Corte Constitucional, MP. EDUARDO CIFUENTES MUÑOZ. Y El Oficio No. 94839809 del 6 de septiembre de 1994 de la Superintendencia de Industria de Industria y Comercio.

61 "Condiciones comerciales normales: que sea consistente con las prácticas normales de los negocios de empresas privadas en el negocio o industria relevante". ACUERDO DE LIBRE COMERCIO ENTRE EL GOBIERNO DE LA REPÚBLICA DE COLOMBIA Y EL GOBIERNO DE LOS ESTADOS UNIDOS DE AMÉRICA, Capítulo 13, Artículo 13.11, Inciso 1. 
establece las medidas antidumping que se pueden adoptar en el desarrollo de las relaciones comerciales internacionales entre Estados Unidos y Colombia. ${ }^{62}$

Las medidas de protección ${ }^{63}$ ideadas consisten en la autorización del País interesado para suspender o aumentar temporalmente, por una sola vez, la desgravación arancelaria pactada en el Acuerdo y siempre que no supere más de un año, sin importar la procedencia del producto en cuestión.

\subsubsection{Derechos compensatorios}

Los derechos compensatorios son aquellas medidas que buscan neutralizar los efectos negativos producidos por las subvenciones ${ }^{64}$ otorgadas por los Gobiernos del país exportador, que causan o amenazan con causar daños materiales a un sector de la producción nacional. ${ }^{65}$

La sección B del capítulo ocho del Acuerdo plantea que para enfrentar las prácticas Dumping y los derechos compensatorios las partes conservarán los derechos y obligaciones adquiridos con el Acuerdo de la OMC, es decir, que tratándose de derechos compensatorios y medidas antidumping tanto Colombia como los EE.UU. deben aplicar el Acuerdo de la OMC que trata esta temática al cual nos referimos en la primera parte de este escrito.

Adicionalmente se advierte tajantemente que en ninguna parte del Acuerdo se impondrá derechos u obligaciones a las partes frente al antidumping y los derechos compensatorios. De ésta forma y como lo mencionamos anteriormente, para poder ejercer medidas antidumping los Gobiernos, previa solicitud por escrito

62 TRATADO DE LIBRE COMERCIO LA REPÚBLICA DE COLOMBIA Y EL GOBIERNO DE LOS ESTADOS UNIDOS DE AMÉRICA, consultado el 23 de Julio de 2012, en: http:// www.sice.oas.org/TPD/AND_USA/Studies/COLResumen_s.pdf. p. 18

63 En este ámbito Colombia cuenta con la siguiente normatividad: Decreto 299 del 10 de Febrero de 1995 y Decreto 2550 del 15 de julio de 2010 que deroga el Decreto 991 del 1 junio de 1998. En el contexto de la CAN en materia de derechos Antidumping son aplicables para el comercio intracomunitario las Decisiones 456 y 457 del 4 de mayo de 1999, y para importaciones de terceros países con la Decisión 283 de 21 de marzo de 1991.

64 El término subvenciones: "A menudo se utiliza como antónimo de impuesto, es decir, una transferencia de dinero público a una entidad del sector privado. Así sucede, por ejemplo, en el caso del diccionario Oxford en línea, en el que se define subvención como "una suma de dinero con cargo a los fondos públicos concedida a una rama de producción o a una empresa para ayudarla a mantener bajo el precio de un producto o de un servicio". ORGANIZACIÓN MUNDIAL DEL COMERCIO, Informe sobre el comercio mundial 2006, II Las Subvenciones, El Comercio y La OMC, B. Definición De Las Subvenciones, 1. Definición de subvención: cuestiones conceptuales, consultado el 18 de Agosto de 2012, en: http://www.wto.org/spanish/res s/booksp s/anrep s/wtr06-2b s. pdf. p. 53

65 SHARMA Robin S. Food And Agriculture Organization Of The United Nations, Las negociaciones comerciales multilaterales sobre la agricultura -manual de referencia, Acuerdo sobre la agricultura, consultado el 18 de agosto de 2012, en: http://www.fao.org/ docrep/003/X7353S/X7353s06.htm 
presentada por la rama de producción nacional o a nombre de ella, tienen la obligación de:

i. Probar la existencia del Dumping, el artículo 2 de la Parte 1 del Acuerdo de la OMC menciona todo el procedimiento que la parte interesada debe seguir para este punto.

ii. Demostrar que el Dumping está causando daño o amenaza causarlo en el sentido del artículo VI del GATT de 1994, lo que se persigue es que el Gobierno, se encargue de demostrar la existencia del daño causado por estas prácticas y esto es lo que señala el artículo 3 de la Parte primer del ya mencionado Acuerdo.

iii. Existencia de una relación causal entre las importaciones objeto de Dumping y el supuesto daño.

Adicionalmente se establecen 3 requisitos para llegar a la imposición de una medida correctiva del Dumping. El artículo 7 de la Parte 1 señala:

i. Se ha iniciado una investigación de conformidad con las disposiciones del artículo 5 , se ha dado un aviso público a tal efecto y se han dado a las partes interesadas oportunidades adecuadas de presentar información y hacer observaciones;

ii. Se ha llegado a una determinación preliminar positiva de la existencia de Dumping y del consiguiente daño a una rama de producción nacional ${ }_{i}$

iii. La autoridad competente juzga que tales medidas son necesarias para impedir que se cause daño durante la investigación.

\subsubsection{Procedimientos para el establecimiento de medidas y derechos antidumping}

Respecto de los procedimientos establecidos para la aplicación de las medidas anteriormente señaladas, el Acuerdo impone a las Partes la obligación de que se realice una investigación previa por una autoridad competente ${ }^{66}$, que se cumpla con el deber de notificar por escrito a la otra parte el inicio del procedimiento proteccionista y que se determine la existencia de un daño grave o una amenaza a una rama de la producción nacional, para lo cual quién tiene la carga de la prueba es el Estado lesionado o las empresas directamente afectadas.

El Acuerdo de la OMC establece el prerrequisito de la notificación por escrito a la contraparte, igualmente impone la necesidad de probar la existencia y magnitud del daño producido por las prácticas Dumping, pero tiene diferencias procedimentales en la medida en que establece la figura de la "Suspensión anticipada del procedimiento y terminación sin imposición de medidas" que el TLC no plantea.

66 La autoridad competente en el caso de Colombia es la subdirección de prácticas comerciales del Ministerio de Comercio, Industria y Turismo y para los Estados Unidos es la U.S International Trade Commission. 
Adicionalmente, el Acuerdo de la OMC implementó un término máximo de duración para las medidas antidumping de cinco años prorrogables, así como la existencia de la "Revisión Judicial" en los procedimientos que se adelanten, lo que no está previsto en el TLC.

Un punto importante que no aparece en el TLC es el reconocimiento que hace el Acuerdo de la OMC de los Países en desarrollo donde se impone la obligación de examinar si la aplicación de medidas antidumping tienen la potencialidad de causar daños a los países en desarrollo y de contemplar soluciones alternativas.

Es importante señalar que la aplicación de estas medidas antidumping si bien ayuda a contrarrestar el efecto negativo que pueden llegar a producir estas prácticas en los sectores de producción nacional, traen consigo un efecto negativo y es que impone altos costos para el país que lo usa ya que, como lo establece el artículo 8.5 del capítulo 8 del Acuerdo, "la parte que baga uso de las medidas deberá proporcionar una compensación de liberación comercial mutuamente acordada".

Esta compensación se da en forma de concesión, para que los efectos que se produzcan como consecuencia de la aplicación de estas medidas, sean sustancialmente equivalentes en el comercio o en el valor de los impuestos adicionales esperados. Para estos efectos, el Acuerdo dispone de un procedimiento de consulta en los 30 días siguientes a la aplicación de la medida y

advierte que en caso de que tales consultas no resulten en una compensación, la Parte sobre la que van a recaer las medidas tiene la potestad de suspender las concesiones comerciales de la Parte que aplica la medida, para lo cual la parte que va a realizar la suspensión debe notificar por escrito a la otra Parte con 30 días de antelación.

"Artículo 8.5: Compensación:

I. Una Parte que aplique una medida de salvaguardia, luego de consultar con cada Parte contra cuya mercancía se aplique la medida, proporcionará una compensación mutuamente acordada de liberalización comercial en forma de concesiones que tengan efectos sustancialmente equivalentes en el comercio o equivalentes al valor de los impuestos adicionales esperados como resultado de la medida. La Parte que aplica la medida de salvaguardia dará oportunidad para tales consultas en los 30 días posteriores a la aplicación de la medida de salvaguardia.

II. Si las consultas bajo el párrafo 1 no resultan en un Acuerdo de compensación de liberalización comercial dentro del término de 30 días, cualquier Parte contra cuya mercancía es aplicada la medida podrá suspender la aplicación de concesiones comerciales sustancialmente equivalentes al comercio de la Parte que aplica la medida de salvaguardia. Borrador de texto sujeto a autenticación de las Partes de las versiones en español y en inglés y a revisión legal para exactitud, claridad y consistencia. 
III. Una Parte contra cuya mercancía es aplicada la medida notificará por escrito a la Parte que aplica la medida de salvaguardia al menos 30 días antes de suspender las concesiones conforme al párrafo 2 .

IV. La obligación de compensar conforme al párrafo 1 y el derecho a suspender las concesiones conforme al párrafo 2 terminará cuando ocurra lo más tarde de:(a) la terminación de la medida de salvaguardia, o (b) la fecha en la cual la tasa arancelaria regrese a la tasa arancelaria establecida en el Programa al Anexo 2.3 (Eliminación Arancelaria) de la Parte".

\subsubsection{Aplicación práctica de las cuotas compensatorias en un caso concreto}

"A partir del 2006, la Secretaría de Economía ha impuesto sistemáticamente cuotas compensatorias inferiores al margen de Dumping encontrado, beneficiando de manera injustificada e ilegal a las mercancías extranjeras en perjuicio de la producción nacional. Esta práctica además de ser ilegal se traduce en un gran obstáculo para que los productores nacionales decidan solicitar el inicio de investigaciones en contra de la importación de mercancías en condiciones de Dumping o de subsidios, quienes consideran que el costo beneficio de una investigación es mínimo, ya que en el mejor de los casos, después de demostrar mediante un procedimiento muy complejo, largo y costoso, que las mercancías se importan a precios con Dumping o subsidios y causan daño a la producción nacional, por lo que es legalmente procedente imponer una cuota compensatoria equivalente al margen de Dumping encontrado (100), la Secretaría de Economía decide ilegal y arbitrariamente imponer una cuota compensatoria inferior (60), beneficiando así a las mercancías extranjeras y desalentando a los productores nacionales". ${ }^{67}$

"Al igual que México, otros países como Estados Unidos, también han interpretado equivocadamente el objetivo de las cuotas compensatorias, a favor de su producción nacional, pretendiendo "compensar" el daño causado a sus productores por las importaciones a precios Dumping. El Gobierno estadounidense, a través de la denominada Enmienda Byrd, ha pretendido repartir los ingresos recaudados por el pago de cuotas compensatorias entre los productores nacionales afectados por la práctica desleal, a efecto de "compensar" monetariamente el daño causado por las importaciones en condiciones de Dumping o subvenciones. Ambas interpretaciones son equivocadas y no tienen sustento en la las disposiciones legales de la Organización Mundial del Comercio (OMC). El criterio de México, al considerar que la finalidad de la cuota compensatoria consiste en reestablecer las condiciones de competencia, y compensar un desequilibrio comercial favorece a los exportadores dumpeadores extranjeros, en tanto que la interpretación de Estados Unidos, consistente en una compensación monetaria beneficia a sus productores

67 SALDAÑA PÉREZ Juan Manuel. Problemática Jurídica sobre el Comercio Exterior, consultado el 18 de Agosto de 2012, en: http://www.derecho.unam.mx/investigacion/publicaciones/ revista-cultura/pdf/CJ4_Art_1.pdf, pp. 11-14 
nacionales (estadounidenses). Ambas posturas son erróneas, pues la finalidad de la cuota compensatoria está determinada en la legislación sobre la materia y consiste en condenar-castigar, contrarrestar, impedir y desalentar el Dumping, por lo que no es posible atribuirle un objetivo distinto" ${ }^{168}$.

\subsection{Sectores de la Producción Nacional sobre los cuales es necesario MITIGAR EL RIESGO Y MAXIMIZAR LOS BENEFICIOS EN LA COMPETITIVIDAD DE Colombia frente a Estados Unidos}

Dentro del desarrollo de las negociaciones adelantadas para llevar a término el TLC con Estados Unidos, en la décimo primera ronda celebrada en julio de 2005, se creó "la Agencia Interna para la Productividad y la Competitividad" que se encargó de plantear estrategias para enfrentar las problemáticas que se pueden presentar con el TLC. ${ }^{69}$

\section{i. En el sector de infraestructura}

La Agencia presentó una propuesta frente a la eficiencia del sector productivo con la que cuenta el País y básicamente planteó la necesidad de que Colombia modifique la infraestructura establecida para poder competir frente a los nuevos retos que aparezcan dentro del desarrollo de las relaciones comerciales que se den con los Estados Unidos. Es así como esta agenda identificó las siguientes prioridades ${ }^{70}$ :

- Consolidación de la red vial.

- Modificación de la estructura aérea.

- Ampliación de la capacidad del sistema portuario.

- Consolidación del sistema del transporte fluvial.

- Articulación de la red férrea.

- Desarrollo de las zonas logísticas y fronterizas.

Para estos fines el documento plantea que Colombia deberá invertir doscientos seis (206) billones de pesos, contados para el año de 2005, entre los años de 2006 y 2019, que estará repartido para el sector público con un porcentaje del cuarenta y cinco por ciento $(45 \%)$ y para el sector privado con un porcentaje del cincuenta y cinco por ciento $(55 \%){ }^{71}$

68 Ibídem.

69 Tratado de libre comercio Colombia- Estados Unidos, Resumen, consultado el 23 de Julio de 2012 en: http://www.sice.oas.org/TPD/AND_USA/Studies/COLResumen_s.pdf. pág. 4

70 Ibídem.

71 lbídem. 
Adicionalmente la Agenda plantea la necesidad de establecer la creación de corredores de flujo de comercio con el fin de que estos sirvan como vinculo conector entre las actividades comerciales y los procesos de producción nacional. ${ }^{72}$

\section{ii. En el sector empresarial, tecnológico y de capital humano}

Este documento también resalta la necesidad de establecer un mecanismo que ayude a fortalecer el sector productivo, el cual encuentra su núcleo en los bajos niveles de escolaridad y capacitación laboral, este punto es fundamental para que el país se encuentre al menos sumariamente en condiciones equitativas para competir comercialmente con los sectores productivos de los Estados Unidos. Otra problemática a solucionar es la existencia de obstáculos para el financiamiento empresarial, el poco desarrollo tecnológico y la falta de compensaciones para los trabajadores. ${ }^{73}$

Frente a todas estas problemáticas la Agenda propuso ${ }^{74}$ :

"1. La integración de empresas pequeñas y medianas, como un mecanismo de integración competitiva.

2. Se busca el desarrollo asociativo, por medio de la integración vertical, creación de clusters y alianzas estratégicas.

3. Es necesario desarrollar el campo del mercado de capitales al igual que el campo de fondos de capital de riesgos privados y el acceso al crédito.

4. El desarrollo del fomento en la gestión del medio ambiente en el ámbito del cuidado y la calidad mediante la creación de un mecanismo regulatorio e institucional.

5. Desarrollar los puntos de investigación e innovación tecnológica respecto del ámbito del sector productivo.

6. Promover la explotación de los recursos genéticos, la biodiversidad, la biotecnología y el sector agroalimentario e industrial.

7. Impulsar la calidad y volumen para los programas de promoción de capacitación laboral enfatizando en la investigación, ciencia y tecnología."75 


\section{iii. En el sector de las telecomunicaciones}

Esta Agenda plantea la importancia de la existencia de una sociedad informada a la que se pretende llegar por medio de un plan nacional de desarrollo de las Tecnologías de la Información y la Comunicación (Tics), perfeccionamiento de la cobertura de servicios de comunicaciones y aumento de los niveles requeridos para el acceso a las telecomunicaciones. ${ }^{76}$

Adicionalmente se resalta la importancia de establecer un marco normativo completo y riguroso que sirva para impulsar la competencia y la innovación tecnológica. ${ }^{77}$

\subsection{RIESGOS PARA LOS EMPRESARIOS Y LA NORMATIVIDAD COLOMBIANA}

Anteriormente se expuso que la política de protección a la competencia establecida en el TLC entre Colombia y Estados Unidos dispone que cada país Parte mantendrá la vigencia de su regulación nacional, por lo que resulta de vital importancia analizar los riesgos que pueden surgir de la interacción normativa entre el régimen colombiano y el estadounidense. ${ }^{78}$

En otros términos, resulta esencial analizar cuales serían los posibles riesgos que se presentan por los conflictos que aparecen entre los diferentes regímenes legales que se aplican en materia de competencia que no persiguen los mismos fines pero que son aplicables a las mismas conductas, lo cual se presenta por la existencia de normas con diferentes jurisdicciones. Y finalmente se debe rescatar cuales serían los mecanismos que permitirán conciliar estás aparentes incompatibilidades.

$\mathrm{Al}$ respecto, un estudio realizado por la Superintendencia de Industria y Comercio (en adelante SIC) señala que una interacción normativa de esta clase se presenta por:

i. La existencia de prácticas comerciales restrictivas de la competencia.

ii. Que se realicen y/o produzcan efectos en:

- La zona de libre comercio entre Estados Unidos y Colombia

- En los mercados Andinos, incluyendo los Colombianos ${ }^{\prime \prime 79}$

Por lo tanto advierte la SIC que existe la posibilidad de que se presenten los siguientes riesgos al momento de aplicar la normativa de la protección a la competencia, asi ${ }^{80}$ : 
i. Qué una práctica esté prohibida para un extremo de la relación comercial y para el otro no.

ii. Que los mecanismos de defensa para contrarrestar los efectos nocivos de las prácticas desleales no sean similares para ambas partes.

iii. Que las sanciones aplicables no sean similares para las partes del conflicto.

Para responder a esto la SIC concluye que es necesario analizar cuáles son las conductas que están prohibidas en la legislación colombiana y cuáles son las condiciones de aplicabilidad que están incorporadas en la normativa de la CAN.

En éste sentido, en primer lugar la SIC se basa en la Decisión 608 de 2005 de la CAN para concluir que los mecanismos de defensa frente a las conductas violatorias de las políticas de protección a la competencia reguladas en ésta decisión se aplicarán cuando se realicen las siguientes conductas:

- En el territorio de uno o más países miembro cuyos efectos se produzcan en el territorio de uno o más países miembros.

- En el territorio de uno o más países no miembro cuyos efectos se produzcan en el territorio de dos o más países miembros.

De conformidad con lo anterior, se hace referencia a la legislación de protección a la competencia existente en Colombia y el primer escalón es la Constitución Nacional colombiana, dado esta es la base de la organización de la regulación del Estado colombiano:

"Artículo 88: La ley regulará las acciones populares para la protección de los derechos e intereses colectivos, relacionados con el patrimonio, el espacio, la seguridad y la salubridad públicos, la moral administrativa, el ambiente, la libre competencia económica y otros de similar naturaleza que se definen en ella.

También regulará las acciones originadas en los daños ocasionados a un número plural de personas, sin perjuicio de las correspondientes acciones particulares.

Así mismo, definirá los casos de responsabilidad civil objetiva por el daño inferido a los derechos e intereses colectivos".

Este artículo instituye el reconocimiento la libre competencia como un derecho colectivo.

"Artículo 333. La actividad económica y la iniciativa privada son libres, dentro de los límites del bien común. Para su ejercicio, nadie podrá exigir permisos previos ni requisitos, sin autorización de la ley. 
La libre competencia económica es un derecho de todos que supone responsabilidades. La empresa, como base del desarrollo, tiene una función social que implica obligaciones. El Estado fortalecerá las organizaciones solidarias y estimulará el desarrollo empresarial.

El Estado, por mandato de la ley, impedirá que se obstruya o se restrinja la libertad económica y evitará o controlará cualquier abuso que personas o empresas bagan de su posición dominante en el mercado nacional.

La ley delimitará el alcance de la libertad económica cuando así lo exijan el interés social, el ambiente y el patrimonio cultural de la Nación".

"Artículo 334. La dirección general de la economía estará a cargo del Estado. Este intervendrá, por mandato de la ley, en la explotación de los recursos naturales, en el uso del suelo, en la producción, distribución, utilización y consumo de los bienes, y en los servicios públicos y privados, para racionalizar la economía con el fin de conseguir el mejoramiento de la calidad de vida de los babitantes, la distribución equitativa de las oportunidades y los beneficios del desarrollo y la preservación de un ambiente sano.

El Estado, de manera especial, intervendrá para dar pleno empleo a los recursos bumanos y asegurar que todas las personas, en particular las de menores ingresos, tengan acceso efectivo a los bienes y servicios básicos. También para promover la productividad y la competitividad y el desarrollo armónico de las regiones".

Como podemos observar que el artículo trecientos treinta y tres (333) de la Constitución Política Colombiana, consagra un derecho limitado ya que si bien por un lado otorga el derecho a la libre competencia, por otro establece una responsabilidad, y esta consiste en darle una función social a toda empresa que exista en el mercado. Y que adicionalmente está el artículo 88 que por medio de acciones populares, de grupo, de tutela protege de los derechos colectivos.

En tercer lugar, señalamos que la legislación colombiana establece que las infracciones a las disposiciones del derecho de la competencia ejercidas en el exterior con efectos en el mercado nacional serán objeto de conocimiento de la autoridad nacional.

Las leyes regulatorias de la materia en Colombia son:

- Ley 256 de 1996 y la Decisión 486 del 2000.

- Ley 155 de 1959.

- Decreto 1302 de 1964.

- Decreto 2153 de 1992.

- Ley 590 de 2000.

- Ley 1340 de 2009.

- Decreto 2513 de 2005.

- Circulares de la Superintendencia de Industria y Comercio. 
Adicionalmente están las siguientes sentencias de la Corte Constitucional sobre la libre competencia establecida constitucionalmente en el art. 333 así:

La Corte Constitucional en sentencia C-197 de 2012 del catorce (14) de marzo con ponencia del Dr. Jorge Ignacio Pretelt Chaljub dijo:

"La Corte ba sostenido que el artículo 333 reconoce dos tipos de libertades: la libertad de empresa y la libre competencia. La libertad de empresa es la facultad de las personas de "(..) afectar o destinar bienes de cualquier tipo (principalmente de capital) para la realización de actividades económicas para la producción e intercambio de bienes y servicios conforme a las pautas o modelos de organización típicas del mundo económico contemporáneo con vistas a la obtención de un beneficio o ganancia". La libre competencia, por su parte, consiste en la facultad que tienen todos los empresarios de orientar sus esfuerzos, factores empresariales y de producción a la conquista de un mercado, en un marco de igualdad de condiciones. Según la jurisprudencia constitucional, esta libertad comprende al menos tres prerrogativas: (i) la posibilidad de concurrir al mercado, (ii) la libertad de ofrecer las condiciones y ventajas comerciales que se estimen oportunas, y (iii) la posibilidad de contratar con cualquier consumidor o usuario. En este orden de ideas, esta libertad también es una garantía para los consumidores, quienes en virtud de ella pueden contratar con quien of rezca las mejores condiciones dentro del marco de la ley y se benefician de las ventajas de la pluralidad de oferentes en términos de precio y calidad de los bienes y servicios, entre otros. Para garantizar la libre competencia, el Estado es entonces responsable de eliminar las barreras de acceso al mercado y censurar las prácticas restrictivas de la competencia, como el abuso de la posición dominante o la creación de monopolios". ${ }^{81}$

"No obstante, en los términos del artículo 333, las libertades económicas no son absolutas. Esta disposición señala que la empresa tiene una función social que implica obligaciones, prevé que la libre competencia supone responsabilidades, e indica que la ley delimitará el alcance de la libertad económica "cuando así lo exijan el interés social, el ambiente y el patrimonio cultural de la Nación". Con base en esta disposición de la Carta, la jurisprudencia constitucional ba concluido que las libertades económicas son reconocidas a los particulares por motivos de interés público. Por esta razón, en reiterada jurisprudencia, esta Corporación ba aclarado que las libertades económicas no son en sí mismas derechos fundamentales" ${ }^{12}$.

\section{La Corte Constitucional en sentencia C-524 de 1995 del dieciséis (16) con ponencia del Dr. CARLOS GAVIRIA DIAZ:}

"La libertad de empresa le otorga a toda persona el derecho de ejercer y desarrollar una determinada actividad económica, de Acuerdo con el modelo económico u organización institucional que, como ya se anotó, en nuestro país lo es la economía de mercado, libertad que al tenor del Estatuto Supremo no es absoluta, ya que el

81 Para profundizar consulte: Demanda de inconstitucionalidad contra el artículo 52.1 de la ley 1438 de 2011 "Por medio de la cual se reforma el Sistema General de Seguridad Social en Salud y se dictan otras disposiciones. Sentencia C-197 del 14 de marzo del 2012 de la Corte Constitucional, M.P. JORGE IGNACIO PRETELT CHALJUB. 
legislador está facultado para limitar o restringir su alcance cuando así lo exijan "el interés social, el ambiente y el patrimonio cultural de la Nación". Además, no puede olvidarse que la empresa, como base del desarrollo, tiene una función social qué cumplir, la que implica ciertas obligaciones, y que la libre competencia económica "supone responsabilidades". El Estado al regular la actividad económica cuenta con facultades para establecer límites o restricciones en aras de proteger la salubridad, la seguridad, el medio ambiente, el patrimonio cultural de la Nación, o por razones de interés general o bien común. En consecuencia, puede exigir licencias de funcionamiento de las empresas, permisos urbanísticos y ambientales, licencias sanitarias, de seguridad, de idoneidad técnica". ${ }^{83}$

Todo lo anterior nos lleva a la conclusión de que en nuestra legislación existe un modelo de competencia establecido sobre la libertad y las garantías económicas que requiere la existencia de cinco (5) supuestos fundamentales:

- Propiedad privada.

- Libre iniciativa privada.

- Libertad de empresa.

- Libertad de competencia.

- La intervención del Estado, cuando hay fallas del mercado.

Finalmente, encontramos que en el artículo 13.3 del capítulo trece 13 del TLC pactado entre Colombia y Estados Unidos, las partes se comprometen a idear mecanismos que permitan que las respectivas autoridades entablen vínculos de cooperación y coordinación en la aplicación de la política de competencia, lo cual incluye la necesidad de incorporar sistemas de consulta y notificación de la información que afecte o sea de interés para la otra parte, así:

Artículo 13.3: Cooperación

1. Las Partes acuerdan cooperar en el área de la política de competencia. Las Partes reconocen la importancia de la cooperación y la coordinación entre sus Borrador de texto sujeto a autenticación de las Partes de las versiones en español y en inglés y a revisión legal para exactitud, claridad y consistencia respectivas autoridades para lograr la aplicación efectiva de la legislación de libre competencia en la zona de libre comercio.

2. En consecuencia, las Partes cooperarán en asuntos relativos a la aplicación de la legislación de libre competencia, incluyendo la notificación de casos que afecten intereses importantes de otra Parte, consultas e intercambio de información relacionada con la aplicación de la legislación y las políticas de competencia de cada Parte.

83 Para ver más sobre el tema: Demanda de inconstitucionalidad contra el artículo 19 de la ley 30 de 1986. Sentencia C-524 del 16 de noviembre 1995 de la Corte Constitucional, M.P. Dr. CARLOS GAVIRIA DIAZ. 
Adicionalmente en el artículo 13.4 del capítulo 13 del Acuerdo se implementa la creación de un Grupo de Trabajo que busca facilitar la comunicación de ambas partes frente a la política de la competencia, tal y como se observa a continuación:

\section{Artículo 13.4: Grupo de Trabajo}

Las Partes establecerán un grupo de trabajo integrado por representantes de cada Parte. El grupo de trabajo procurará promover el mayor entendimiento, comunicación y cooperación entre las Partes en relación con las materias cubiertas por este Capítulo. El grupo de trabajo informará sobre el estado de sus esfuerzos a la Comisión dentro de los tres años siguientes a la entrada en vigor de este Acuerdo, y podrá hacer recomendaciones apropiadas para acciones futuras que puedan continuar promoviendo el logro de los objetivos de este Artículo.

En atención a lo anterior se concluye que el TLC incorpora dentro de su normativa mecanismos que abogan por la aplicación coordinada de los regímenes legales de la competencia cuando se ven obligados a coexistir e interactuar dentro de los procesos de integración comercial que involucran diferentes jurisdicciones, esto con el fin de evitar que ésta clase de incompatibilidades generen un impacto negativo para las ramas o sectores de la producción nacional y para los agentes que intervienen en las relaciones comerciales internacionales.

\section{CONCLUSIONES}

Las políticas de competencia que abogan por la transparencia y la cooperación en las relaciones comerciales que tienen lugar entre los Estados en virtud de los Tratados de Libre Comercio son un punto de vital importancia que merece análisis y crítica, en la medida en que de ellas depende la forma como se va a adelantar el proceso de intercambio comercial y la generación de beneficios que se buscan con estos pactos bilaterales.

En este sentido la introducción de políticas serias y claras de competencia en los Tratados de Libre Comercio constituyen una herramienta esencial para proteger las economías y las industrias nacionales y garantizar que los beneficios de un mayor tráfico comercial alcance a todos los productores nacionales.

Dentro de estas políticas de sana y leal competencia la regulación del Dumping es esencial toda vez que a través de ella se eliminan los efectos negativos de esta práctica y se brindan condiciones de negocios más equitativas a los productores nacionales. En este sentido las medidas antidumping deben ser incorporadas en estos convenios bilaterales de forma coherente y eficaz, para lo cual los Estados han optado por acudir a las reglamentaciones y Acuerdos incorporados por la Organización Mundial del Comercio el cual ha sido de- 
nominado "Acuerdo Relativo a la Aplicación del Artículo VI del Acuerdo General sobre Aranceles Aduaneros y Comercio de 1994".

En primer lugar es necesario mencionar que la OMC como organismo internacional encargado regular y establecer la normatividad dirigida a regular las prácticas de competencia desleal y de implementar los mecanismos que están dirigidos a contrarrestar sus efectos negativos, ha adelantado un gran trabajo de investigación y de implementación normativa que satisface las necesidades que se generan dentro de las economías internacionales en la medida en que otorga las herramientas necesarias para enfrentar el ejercicio de las prácticas que provocan un impacto negativo en las industrias de los Estados.

En segundo lugar se resalta la forma como Colombia ha venido enfrentando la posibilidad de que estas prácticas desleales se ejerzan en el desarrollo de las relaciones comerciales que se adelantan en virtud de la firma y ratificación de los Tratados de Libre Comercio, los cuales son herramientas de gran importancia para el desarrollo de la vida comercial y social de las naciones.

Es así como es posible afirmar que Colombia dispone de las herramientas necesarias para enfrentar y eliminar los efectos negativos que se producen por el ejercicio de las prácticas Dumping, dado que a lo largo del análisis que se adelantó en el presente documento fue posible observar que en todos los Tratados de Libre Comercio que hasta el momento se han firmado y ratificado se ha acudido a la normatividad de la Organización Mundial del Comercio, la cual se concreta en el Acuerdo de 1994 y que hace parte de los Acuerdos firmados con Canadá, Corea del Sur y Estados Unidos.

El Tratado de Libre Comercio entre Colombia y Estados Unidos se enfrenta con la problemática de tener que encontrar los medios y las soluciones adecuadas para impedir que los sectores productivos de ambos países se vean afectados por las diferentes prácticas que se desarrollen dentro de las relaciones comerciales que puedan afectar la libre y sana competencia entre los entes económicos que entren a desenvolverse en el comercio internacional de estos dos países.

Si bien nuestra normativa general de libre competencia y de competencia desleal se ajusta a las exigencias y principios del TLC, preocupa que ciertos sectores de nuestra economía se vean actualmente amenazados por la competencia extranjera que aún goza de privilegios que nosotros aún no hemos establecido o cuando menos no hemos logrado aplicar eficazmente. Nos referimos a las políticas de subsidios, ayudas estatales y regímenes de excepción en materia de libre competencia, que EE.UU. sigue manejando y que les otorga a sus empresarios ventajas significativas en un mercado internacional.

En cuando a las conductas de Dumping y subvenciones consideramos necesario dar aplicación efectiva a los procedimientos trazados dentro del marco de la OMC pero sobre todo divulgar entre el sector empresarial el conocimiento de estas normas con el fin de que sean ellos quienes puedan ser agentes activos del control de estas conductas ilícitas. 
No se puede olvidar que Colombia es un país en desarrollo que requiere del establecimiento de mecanismos que fortalezcan, como lo señala la "Agencia Interna para la Productividad y la Competitividad", los sectores productivos, la infraestructura, el sector empresarial, el sector tecnológico, el capital bumano, el sector de las telecomunicaciones, entre otros; todo esto con el fin de ser un país suficientemente competitivo frente a Estados Unidos y evitar que los sectores económicos nacionales se vean afectados en las relaciones comerciales con este país.

Por ésta razón el 16 de febrero del año 2012 se expide la Directiva Presidencial No. 00001 de 2012 sobre "La coordinación para el aprovechamiento del Tratado de Libre Comercio con Estados Unidos" en la que señala tres grandes áreas sobre las que es necesario iniciar una tarea de coordinación con miras a lograr una implementación fructífera de este acuerdo de liberación comercial, esto es a) implementación normativa ${ }_{i}$ b) adecuación institucional, y c) aprovechamiento comercial. Para lo cual, señala que es necesario que todas las instituciones involucradas cooperen en la realización de las actividades que se mencionan a continuación:

1. Identificar las oportunidades, sectores, productos y servicios estratégicos para el aprovechamiento del Tratado de Libre Comercio con Estados Unidos (TLC), buscando la diversificación de la oferta exportable del país.

2. Coordinar la agenda de trabajo con empresarios y gremios a nivel nacional y regional, con el fin de identificar oportunidades y destinos potenciales de los productos y servicios en el mercado americano.

3. Establecer un diálogo constante con el sector privado, los gremios nacionales y regionales y las autoridades regionales, con el objetivo de identificar las necesidades de las empresas, los sectores y las regiones, para el aprovechamiento del TLC.

4. Brindar asesoría en la implementación de la Política de Innovación para empresas con alto potencial exportador a Estados Unidos.

5. Identificar las dificultades para el acceso al mercado de productos, sectores y regiones, apoyar a las entidades responsables para la implementación de acciones encaminadas a superar las dificultades.

6. Apoyar la estrategia de Proexport para la promoción y divulgación de las ventajas y oportunidades del TLC para los inversionistas nacionales y extranjeros que permitan aprovechar el mercado colombiano como plataforma exportadora, en coordinación con la estrategia trazada por el Ministerio de Comercio Exterior.

7. Brindar asesoría en la adecuación institucional de las entidades relacionadas con controles sanitarios y fitosanitarios (ICA e Invima), impulsar y hacer seguimiento de las actividades que se requieran para adecuarlas a los requerimientos del TLC. 
De ésta manera, en la medida en que los países parte de estos tratados de liberación comercial lleven a cabo un ejercicio legal y de conformidad con lo que regla la normatividad acordada, los sectores productivos no sufrirán los efectos negativos producidos por las prácticas restrictivas de la competencia, el Dumping y las Subvenciones.

\section{BIBLIOGRAFÍA}

\section{DOCUMENTOS}

CÁMARA DE COMERCIO DE BOGOTÁ. Guía Práctica "Conoce las condiciones de acceso a mercados y las medidas de defensa comercial" (2009), Bogotá.

EL TIEMPO. Tratado de Libre Comercio entre Colombia y Estados Unidos, EL TIEMPO No. $1,(2012)$.

MINISTERIO DE COMERCIO EXTERIOR. Guía de Dumping y Subsidios en Colombia (2001), Bogotá.

MINISTERIO DE COMERCIO, INDUSTRIA Y COMERCIO. Dirección de Comercio Exterior, Subdirección de Prácticas Comerciales, Dumping y Subsidios (2010), Bogotá.

MINISTERIO DE COMERCIO, INDUSTRIA Y COMERCIO. Dumping y Subsidios, ¿Cómo demostrar la existencia de "Dumping o Subvención en las importaciones? (2010), Bogotá.

MINISTERIO DE COMERCIO, INDUSTRIA Y TURISMO. Dumping y Subsidios (2010) Bogotá.

MINISTERIO DE COMERCIO, INDUSTRIA Y TURISMO. Resolución 0026 de enero 5 de 2012, "Por la cual se resuelve una solicitud de Revocatoria Directa", Bogotá.

\section{JURISPRUDENCIA}

Acción de tutela instaurada por Asociación De Pensionados Del Caquetá -Asopenca-Contra Caja De Previsión Social Departamental Del Caquetá Y Departamento Del Caquetá. Sentencia T-241 del 23 de junio de 1993 de la Corte Constitucional, M.P. EDUARDO CIFUENTES MUÑOZ.

Acción de tutela instaurada por Marcelino Rodríguez Rojas contra Terpel Sur SA. - TERPEL. Sentencia T-375 de 1997 de la Corte Constitucional, M.P. EDUARDO CIFUENTES MUÑNOZ.

Demanda de inconstitucionalidad contra el artículo 19 de la ley 30 de 1986. Sentencia C-524 del 16 de noviembre 1995 de la Corte Constitucional, M.P. CARLOS GAVIRIA DIAZ. 
Demanda de inconstitucionalidad contra el artículo 52.1 de la ley 1438 de 2011 "Por medio de la cual se reforma el Sistema General de Seguridad Social en Salud y se dictan otras disposiciones. Sentencia C-197 del 14 de marzo del 2012 de la Corte Constitucional, M.P. Jorge Ignacio Pretelt Chaljub.

Oficio No. 94839809 del 6 de septiembre de 1994 de la Superintendencia de Industria de Industria y Comercio.

INFORMACIÓN ON LINE:

BARBOSA MARIÑO J. y LOZANO ORTIZ DE ZÁRATE M., ¿Cómo leer el tratado de libre comercio Colombia-Estados Unidos de América?, resultados preliminares de la línea de investigación tratado de libre comercio, Colombia-estados unidos (2008), consultado el 18 de Agosto de 2012, en: http://www.javeriana.edu.co/juridicas/pub rev/ documents/7BarbosayLozano 001.pdf.

COMUNIDAD ANDINA. Competencia, consultado el 19 de Mayo de 2012, en: http:// www.comunidadandina.org/competencia/competencia int.htm

COMUNIDAD ANDINA. Dumping, consultado el 19 de Mayo de 2012, en: http:// www.comunidadandina.org/competencia/Dumping.htm. Y. MINISTERIO DE COMERCIO, INDUSTRIA Y TURISMO. Dumping y Subsidios (2007) Bogotá.

COMUNIDAD ANDINA. Reseña bistórica, consultado el 21 de agosto de 2014, en: http://www.comunidadandina.org/Seccion. aspx?id=195\&tipo=QU\&title=resenahistorica

CORREA C. Jorge. Portafolio.co., Historia de un proceso que tardó 7 años, consultado el 17 de Agosto de 2012, en: http://www.portafolio.co/negocios/historia-unproceso-que-tardo-7-anos

DEPÓSITO DE DOCUMENTOS DE LA FAO, Departamento de Cooperación Técnica, Las negociaciones comerciales multilaterales sobre la agricultura-manual de referencia L Acuerdo sobre la agricultura, consultado el 18 de Agosto de 2012, en: http://www. fao.org/docrep/003/X7353S/X7353s06.htm

ESCOBAR RUBIO Jairo. Interacción de normas de competencia: colombianas, de la comunidad andina y de los Estados Unidos (2005, consultado el 23 de Junio de 2012, en: http:// www.sic.gov.co/recursos user/documentos/articulos/Interaccion_Normas.pdf

IBÁÑEZ PARRA Oscar. El modelo de competencia económica practicable del TLC entre Colombia y Estado Unidos, consultado el 19 de Mayo de 2012, en: http://www.usergioarboleda. edu.co/civilizar/revista9/MODELO COMPETENCIA PRACTICABLE TLC ENTRE COLOMBIA ESTADOS UNIDOS.pdf 
LA ORGANIZACIÓN PARA LA COOPERACIÓN Y DESARROLLO ECONÓMICO (OCDE). Acerca de la OCDE, ¿Quées la OCDE?, consultado el 20 de agosto de 2014, en: http://www.oecd.org/centrodemexico/laocde/

LA ORGANIZACIÓN PARA LA COOPERACIÓN Y DESARROLLO ECONÓMICO (OCDE). La competencia en América Latina y el caribe, Los 10 años del foro latinoamericano de competencia OCDE-BID, consultado el 20 de agosto de 2014, en: http:// www.oecd.org/competition/latinamerica/LACF10thAnniversaryBrochureES.pdf

MINISTERIO DE COMERCIO INDUSTRIA Y TURISMO. ABC del Acuerdo Comercial Colombia con Panamá, consultado el 19 de agosto de 2014, en: http://www. mincit.gov.co/tlc/publicaciones.php?id=7974

MINISTERIO DE COMERCIO INDUSTRIA Y TURISMO. ABC del Acuerdo Comercial Colombia con Costa Rica consultado el 19 de agosto de 2014, en: http://www. mincit.gov.co/publicaciones. . hp? $\mathrm{id}=5812$

MINISTERIO DE COMERCIO INDUSTRIA Y TURISMO. ABC del Acuerdo Comercial Colombia con Israel, consultado el 19 de agosto de 2014, en: http://www.tlc. gov.co/publicaciones.php?id=8047

MINISTERIO DE COMERCIO, INDUSTRIA Y TURISMO. Acuerdo de promoción comercial entre la república de Colombia y Canadá, Colombia, consultado el 10 de Julio de 2013, en: https://www.mincomercio.gov.co/tlc/publicaciones.php?id=16157

MINISTERIO DE COMERCIO, INDUSTRIA Y TURISMO. Acuerdo Comercial y de Inversión, Acuerdos Vigentes, consultado el 19 de agosto de 2014, en: http://www.tlc. gov.co/publicaciones.php?id=5398

MINISTERIO DE COMERCIO, INDUSTRIA Y COMERCIO. Operaciones Comerciales Normales, consultado el 21 de agosto de 2014, en: http://www.mincit.gov.co/ publicaciones. php?id $=11982$

MINISTERIO DE COMERCIO, INDUSTRIA Y TURISMO. Dumping, Resumen de investigaciones Antidumping Adelantadas por Colombia, consultado el 30 de septiembre de 2014, en: http://www.mincit.gov.co/publicaciones.php?id=12207

MINISTERIO DE COMERCIO, INDUSTRIA Y TURISMO. Lámina lisa galvanizada, consultado el 30 de septiembre de 2014, en: http://www.mincit.gov.co/ publicaciones. . hp? id $=6332$

MINISTERIO DE COMERCIO, INDUSTRIA Y TURISMO. Películas flexibles de PVC y películas rígidas de PVC, consultado el 4 de octubre de 2014, en: http://www. mincit.gov.co/publicaciones.php?id=5894 
MINISTERIO DE COMERCIO, INDUSTRIA Y TURISMO. Tornillos y tuercas, consultado el 4 de octubre de 2014, en: http://www.mincit.gov.co/publicaciones. php?id $=15817$

MINISTERIO DE COMERCIO, INDUSTRIA Y TURISMO. Texto Final del acuerdo de promoción comercial entre Colombia y Canadá. Colombia, consultado el 10 de Julio de 2013, en: https://www.mincomercio.gov.co/tlc/publicaciones.php?id=681

ORGANIZACIÓN MUNDIAL DEL COMERCIO. Acuerdo Relativo a la Aplicación del Artículo VI del Acuerdo General sobre Aranceles Aduaneros y Comercio de 1994, consultado el 29 de Julio de 2012, en: http://www.wto.org/spanish/docs s/legal s/19. adp 01 s.htm\#Articlel

ORGANIZACIÓN MUNDIAL DEL COMERCIO. Glosario de Términos, consultado el 20 de Agosto de 2014, en: http://www.wto.org/spanish/thewto s/glossary s/ glossary s.htm

ORGANIZACIÓN MUNDIAL DEL COMERCIO. Glosario de Términos., consultado el 20 de Agosto de 2014, en: http://www.wto.org/spanish/tratop s/tradfa s/ tradfa s.htm

ORGANIZACIÓN MUNDIAL DEL COMERCIO. Información Técnica sobre las Medidas Antidumping, consultado el 18 de Agosto de 2012, en: http://www.wto.org/ spanish/tratop s/adp s/adp info_s.htm

ORGANIZACIÓN MUNDIAL DEL COMERCIO. Informe del Grupo Especial, México - Medidas Antidumping definitivas sobre la carne de bovino y el arroz, reclamación con respecto al arroz del 6 de junio de 2005, consultado el 18 de agosto de 2012, en: WWW. WTO.ORG/SPANISH/TRATOP S/DISPU S/295R A S.DOC.

ORGANIZACIÓN MUNDIAL DEL COMERCIO. Informe sobre el comercio mundial 2006, II Las Subvenciones, El Comercio y La OMC, B. Definición De Las Subvenciones, 1. Definición de subvención: cuestiones conceptuales, consultado el 18 de Agosto de 2012, en: http://www.wto.org/spanish/res s/booksp s/ anrep s/wtr06-2b s.pdf.

ORGANIZACIÓN MUNDIAL DEL COMERCIO. Inversiones, Competencia, Contratación pública, Procedimientos Simplificados consultado el 19 de Mayo de 2012, en: http://www.wto.org/spanish/thewto s/whatis s/tif s/bey3 s.htm\#investment

ORGANIZACIÓN MUNDIAL DEL COMERCIO. Inversiones, Competencia, Contratación pública, Procedimientos Simplificados, consultado el 19 de Mayo de 2012, en: http://www.wto.org/spanish/thewto s/whatis s/tif s/bey3 s.htm\#investment

ORGANIZACIÓN MUNDIAL DEL COMERCIO. La Ronda de Doba, consultado el 23 de Julio de 2013, en: http://www.wto.org/spanish/tratop_s/dda s/dda s.htm 
ORGANIZACIÓN MUNDIAL DEL COMERCIO. La Ronda de Doba., consultado el 23 de Julio de 2013, en: http://www.wto.org/spanish/thewto_s/whatis_s/tif_s/ doha1 s.htm

REDACCIÓN DE EL PAÍS. El País.com.co., El TLC, una aventura que partirá la bistoria de Colombia en dos, consultado el 17 de Agosto de 2012, en: http://www.elpais.com.co/ elpais/economia/noticias/tlc-aventura-cambiara-colombianos.

REDACCIÓN DEL ESPECTADOR, Elespectador.com, consulado el 10 de Julio de 2013, en: HTTP://WWW.ELESPECTADOR.COM/NOTICIAS/ECONOMIA/ ARTICULO-406082-COLOMBIA-Y-COREA-DEL-SUR-FIRMARON-EL-TLC.

RODRÍGUEZ BARZOLA William. Efectos del Dumping en la Comunidad Andina, consultado el 19 de Mayo de 2012, en: http://www.comunidadandina.org/bda/docs/ BO-INT-0004.pdf.

SALDAÑA PÉREZ Juan Manuel. Problemática Jurídica sobre el Comercio Exterior., consultado el 18 de Agosto de 2012, en: http://www.derecho.unam.mx/investigacion/ publicaciones/revista-cultura/pdf/CJ4 Art 1.pdf

SHARMA Robin S. Food And Agriculture Organization Of The United Nations, Las negociaciones comerciales multilaterales sobre la agricultura -manual de referencia, Acuerdo sobre la agricultura, consultado el 18 de agosto de 2012, en: http://www.fao.org/docrep/003/X7353S/X7353s06.htm

Tratado de libre comercio Colombia- Estados Unidos, Resumen, consultado el 23 de Julio de 2012, en: http://www.sice.oas.org/TPD/AND USA/Studies/ COLResumen s.pdf.

\section{DOCTRINA TRADICIONAL}

FIGUEROA CASTRO A. Manual de Exportaciones, La Exportación en Colombia. Universidad del Rosario, Facultad de Administración, Bogotá, Colombia.

CONDON J. BRADLY. El Derecho de La Organización Mundial del Comercio, Tratados, Jurisprudencia y práctica (2007), Cameron May Ltd., Reino Unido.

LUENGO HERNÁNDEZ DE MADRID G. El Derecbo de las Subvenciones en la OMC (2006), Marcial Pons, Ediciones Jurídicas y Sociales S.A., Madrid, Barcelona.

MORENO Luis A., KALMANOVITZ Salomón, SARMIENTO PALACIO Eduardo. Bogotá frente al TLC (2005), Editorial Oveja Negra, Bogotá, Colombia. 


\section{FUENTES NORMATIVAS}

Acuerdo de Libre Comercio entre el Gobierno de la República de Colombia y el Gobierno de los Estados Unidos de América.

Acuerdo de Libre Comercio entre la República de Colombia y Canadá.

Acuerdo de Libre Comercio entre la República de Colombia y la República de Corea.

Acuerdo relativo a la aplicación del artículo VI del Acuerdo General sobre Aranceles Aduaneros y Comercio de 1994.

Artículo VI del Acuerdo General sobre Aranceles Aduaneros y Comercio de 1994.

Decisión 608 de 2005 sobre "Normas para la protección y promoción de la libre competencia en la Comunidad Andina".

Decreto 2153 de diciembre 30 de 1999 "Por el cual se reestructura la Superintendencia de Industria y comercio y se dictan otras disposiciones".

Ley 155 de diciembre 24 de 1959 "Por la cual se dictan algunas disposiciones sobre prácticas comerciales restrictivas". 